OPEN ACCESS

Edited by:

M. Savage,

Queen Mary University of London, United Kingdom

Reviewed by: Stefano Cianfarani, University of Rome Tor Vergata, Italy Jin Soon Hwang, Ajou University, South Korea

${ }^{*}$ Correspondence: Jan M. Wit j.m.wit@/umc.n

Specialty section: This article was submitted to Pediatric Endocrinology, a section of the journal Frontiers in Endocrinology

Received: 09 November 2021 Accepted: 23 November 2021 Published: 16 December 2021

Citation: WitJM(2021) Should Skeletal Maturation Be Manipulated for Extra Height Gain?

Front. Endocrinol. 12:812196. doi: 10.3389/fendo.2021.812196

\section{Should Skeletal Maturation Be Manipulated for Extra Height Gain?}

\author{
Jan M. Wit * \\ Division of Pediatric Endocrinology, Department of Pediatrics, Willem-Alexander Children's Hospital, Leiden University \\ Medical Center, Leiden, Netherlands
}

Skeletal maturation can be delayed by reducing the exposure to estrogens, either by halting pubertal development through administering a $\mathrm{GnRH}$ analogue $(\mathrm{GnRHa})$, or by blocking the conversion of androgens to estrogens through an aromatase inhibitor (Al). These agents have been investigated in children with growth disorders (off-label), either alone or in combination with recombinant human growth hormone (rhGH). GnRHa is effective in attaining a normal adult height $(\mathrm{AH})$ in the treatment of children with central precocious puberty, but its effect in short children with normal timing of puberty is equivocal. If rhGH-treated children with growth hormone deficiency or those who were born small-for-gestational age are still short at pubertal onset, co-treatment with a $\mathrm{GnRHa}$ for 2-3 years increases $\mathrm{AH}$. A similar effect was seen by adding rhGH to $\mathrm{GnRH}$ a treatment of children with central precocious puberty with a poor $\mathrm{AH}$ prediction and by adding $\mathrm{rhGH}$ plus $\mathrm{GnRH}$ a to children with congenital adrenal hyperplasia with a poor predicted adult height on conventional treatment with gluco- and mineralocorticoids. In girls with idiopathic short stature and relatively early puberty, rhGH plus GnRHa increases $\mathrm{AH}$. Administration of letrozole to boys with constitutional delay of growth puberty may increase $\mathrm{AH}$, and $\mathrm{rhGH}$ plus anastrozole may increase $\mathrm{AH}$ in boys with growth hormone deficiency or idiopathic short stature, but the lack of data on attained $\mathrm{AH}$ and potential selective loss-of-follow-up in several studies precludes firm conclusions. GnRHas appear to have a good overall safety profile, while for aromatase inhibitors conflicting data have been reported.

Keywords: growth, skeletal maturation, bone age, adult height, aromatase inhibitors, GnRH analogue, growth hormone, predicted adult height

\section{INTRODUCTION}

There are three therapeutic approaches to increase adult height (AH) for a child with a growth disorder. First, recombinant human growth hormone (rhGH) has been approved for several causes of short stature in children, and in most conditions this treatment (if initiated at a young age) results in an $\mathrm{AH}$ within the genetic target height range of the patient. Second, experiments of nature have suggested that keeping the estrogen exposure low in adolescence might delay skeletal maturation and increase $\mathrm{AH}$, which has led to clinical studies on the efficacy and safety of two forms of medication aimed at reducing estrogen exposure, i.e. gonadotropin-releasing hormone $(\mathrm{GnRH})$ analogues (GnRHas) and aromatase inhibitors (AIs). Third, also the combination of rhGH and a GnRHa or AI has been investigated, 
particularly if the child's height is still low at onset of puberty. This approach is based on the hypothesis that decreasing estrogen exposure slows skeletal maturation and thereby prolongs the time during which rhGH can stimulate linear growth, and thus results in increased $\mathrm{AH}$. In the present paper I review the available clinical data of the second and third approaches.

Multiple "expert opinions" have been published on this topic [e.g. (1-4) in the last 5 years], including two from our own group $(5,6)$. The appearance of many reports in the literature describing the effect of GnRHas or AIs in patients with various forms of growth failure, suggests that these compounds are widely used, despite their uncertain efficacy and safety profile, as well as their off-label status for these indications.

One could wonder why one would spend time to produce yet one more "expert opinion" on this topic, while in virtually all classifications of the levels of evidence (7) the expert opinion is considered to be in the lowest grade of scientific value. The answer is threefold. First, I believe that the cumulative observations of published reports (mainly offering a low grade of evidence when assessed separately) on the use of GnRHas for different specific conditions may still lead to general conclusions on their efficacy in growth disorders. This implies that a detailed analysis of strengths and weaknesses of all published data is warranted, followed by a general assessment. Second, it is unlikely that large randomized controlled trials (RCTs) continuing until $\mathrm{AH}$ will ever be carried out on these interventions in the various growth conditions, so that I fear that for the next decade the level of evidence will remain as low as it currently is. This implies that it is worthwhile to make an effort to extract as much as possible information from the available reports. Third, I believe that it is important to not only assess the results of formal prospective or retrospective clinical trials, but also observations on "experiments of nature" as well as laboratory data and proxy endpoints that provide supportive evidence that a low estrogen concentration (alone or in combination with a growth promoting agent) is associated with delayed skeletal maturation and increased $\mathrm{AH}$. The complex regulation system of longitudinal growth in the epiphyseal growth plate is influenced by multiple endocrine, paracrine, autocrine and intracrine factors (8), but there is no doubt that the major factor influencing the maturation ("senescence") of the growth plate is the exposure to circulating and intracellular estrogen (9).

\footnotetext{
Abbreviations: AH, adult height; AIs, aromatase inhibitors; BA, bone age; BMC, bone mineral content; $\mathrm{BMD}$, bone mineral density; $\mathrm{BMI}$, body mass index; $\mathrm{CA}$, chronological age; $\mathrm{CAH}$, congenital adrenal hyperplasia; CCTs, clinical controlled trials; CDGP, Constitutional delay of growth and puberty; CPP, central precocious puberty; GH, growth hormone; GHD, growth hormone deficiency; GnRH, Gonadotropin Releasing Hormone (GnRH); GnRHa, Gonadotropin Releasing Hormone (GnRH) analogue; HRQoL, Health-related Quality of Life; ISS, idiopathic short stature; $\mathrm{NAH}$, near-adult height; $\mathrm{PAH}$, predicted adult height; LT4, Levothyroxine; RCT, randomized controlled trial; rhGH, recombinant human growth hormone; SDS, standard deviation score; SGA, small for gestational age, also used for a short child born small for gestational age; TH, target height.
}

Indeed, there are many clinical observations supporting the concept that $\mathrm{AH}$ is dependent of the timing and level of circulating estrogens. Untreated children with central precocious puberty (CPP) reach a considerably decreased $\mathrm{AH}$, which can be normalized by timely treatment with a $\operatorname{GnRHa}(10,11)$. At the other end of the spectrum, individuals with decreased circulating estrogens (for example due to hypogonadism) show an extended period of linear growth, resulting in relatively tall stature, even if they are growth hormone deficient (GHD) $(12,13)$. Proof that estrogen is the primary factor responsible for closure of the epiphyseal growth plates was delivered by the observation that the growth plates of a man with a defect of the gene encoding the estrogen alpha receptor never closed, resulting in tall adult stature (and osteoporosis) (14). Further confirmation was provided by observations that men with aromatase deficiency demonstrated a similar growth pattern, except that growth could be stopped by administering estrogen medication (15). Additional support of the positive effect of postponing exposure to estrogens is provided by the observation that a late start of estrogen substitution in girls with Turner syndrome increases $\mathrm{AH}$ (16), although such delay is generally not advised for psychosocial reasons.

The dose-response relationship between estrogen and short term growth, already investigated several decades ago, shows a biphasic curve, with optimal growth occurring at a low estrogen dose (17-20). This was confirmed by the observation that adding low dose estrogen to rhGH treatment increased growth in young girls with Turner syndrome, although the effect was small (21). At the other side of the spectrum, supraphysiological dosages of exogenous estrogens administered to tall female adolescents inhibit growth of the extremities and decrease $\mathrm{AH}$ [but please note that this therapeutic approach has become outdated by potential negative long-term effects on fertility $(22,23)]$. A consequence of the apparent biphasic dose-response curve is that complete suppression of estrogen exposure may be less beneficial for growth than partial suppression. A recent study showed indeed that a threshold level of estrogen of $10 \mathrm{pmol} / \mathrm{L}$ appeared to be needed for an optimal growth rate corresponding to a normal male pubertal growth spurt (24). I shall come back to this issue in paragraph 3, where the use of AIs is discussed.

For each of the referred papers on efficacy reviewed in this paper, I graded the level of evidence (LoE) of studies in a similar fashion as described by the International Consortium on the use of Gonadotropin-Releasing Hormone Analogs in Children (11) (from now on referred to as "International Consortium") using 5 levels: LoE 1 (homogenous randomized controlled trials), 2 (metaanalyses or heterogeneous prospective trials), 3 (case-control studies and retrospective cohorts), 4 (uncontrolled cohort and case studies) or 5 (expert opinions, case reports, and personal observations) (7).

\section{THE EFFECT AND SAFETY OF A GnRH ANALOGUE IN CHILDREN WITH A LOW PREDICTED ADULT HEIGHT}

On the use of GnRHas in pediatrics, two international conferences have been held. The first was convened in 2007 by 
the Pediatric Endocrine Society (PES) from the USA and the European Society for Pediatric Endocrinology (ESPE). The US Public Health grading system (25) was used to grade the evidence and strength of the recommendations, and the participants aimed to adhere to modified appraisal of guidelines research and evaluation (AGREE) criteria (26). The resulting Consensus Statement stated that the efficacy of GnRHas for increasing AH in conditions other than CPP "requires additional investigation and cannot be suggested routinely" (10).

Recently, a second conference was organized by a large number of pediatric endocrine societies (International Consortium) (11), which also included a large section on the use of GnRHas in adolescents with gender dysphoria. The participants aimed to "concisely address topics related to changes in GnRHa usage during childhood and adolescence since the previous consensus statement" and the authors stated that the resulting publication "is not a consensus statement and hence has not been endorsed by any of the societies that designated participating authors." For the purpose of the present review paper, the section on "use of GnRHa in other conditions" is most relevant, and will be discussed in paragraphs 2.2.1 to 2.2.3.

\subsection{The Effect of a GnRH Analogue Alone}

Treatment with a GnRHa as single treatment is usually effective for children with CPP to reach a normal AH $(10,11)$. The positive results of GnRHa treatment in CPP triggered several investigators to study the effect of GnRHa on $\mathrm{AH}$ in short children with relatively early puberty, albeit still within the population reference range. There are two reports of a small positive effect of a GnRHa in such cases. The only placebocontrolled RCT on the effect of a GnRHa on AH was carried out in 24 children with idiopathic short stature (ISS) and 26 with many different diagnoses. Fourteen of them also received rhGH. The authors reported that GnRHa treatment markedly slowed down further BA progression and significantly increased $\mathrm{AH}$ by a mean of $0.6 \mathrm{SD}$, as compared with $\mathrm{PAH}$ at baseline. This effect was independent of sex, the presence or absence of concomitant rhGH, and the presence or absence of a growth-limiting syndrome (27) (LoE 1).

A similar effect was suggested in a recent retrospective cohort study, but only for females (28) (LoE 3). In contrast, four other studies (29-32) (LoE 3) showed no effect. As discussed previously (6), and in line with the International Consortium's opinion (11), my opinion remains that there is insufficient evidence that GnRHa alone increases $\mathrm{AH}$, except for children with CPP.

In order to compensate for the very low height velocity that is often observed during GnRHa treatment in patients with CPP, three approaches have been investigated. First, the combination of GnRHa plus a mini-dose of estrogen was compared with GnRHa alone in patients with CPP in a two year pilot study (33). The results suggested that the low height velocity on GnRHa can be prevented by low-dose estrogen without undue acceleration of bone age (LoE 2), but long-term results have not been reported. Second, the combination of a GnRHa with an anabolic steroid was investigated in two studies with an apparently positive effect on AH compared with matched controls $(34,35)$ (LoE 3), but since then no more data have been presented. Third, rhGH can be added, which will be discussed in paragraph 2.2.5

There are a number of growth disorders in which predicted adult height $(\mathrm{PAH})$ can be low on conventional disease-specific treatment, which motivated studies on the value of adding a GnRHa. Results of this strategy are discussed in the following paragraphs.

\subsubsection{Hypothyroidism}

In a retrospective chart review, height outcome and body mass index (BMI) were analyzed in children with severe longstanding hypothyroidism and bone age (BA) delay treated with LT4 alone or with LT4 plus GnRHa (36). Six GnRHa-treated patients and seventeen controls were followed to $\mathrm{AH}$. At diagnosis, $\mathrm{GnRHa}$ treated patients were older and shorter for chronological age, and more advanced in puberty and BA compared to controls on LT4 alone. Despite these baseline differences (which would predict a lower $\mathrm{AH}$ for the experimental group), both groups showed similar improvements in height standard deviation score (SDS), similar height deficits and comparable $\mathrm{AH}$, which was interpreted as a positive therapeutic effect (LoE 3). Changes in BMI SDS were similar for both groups (36).

\subsubsection{Laron Syndrome}

Children with $\mathrm{GH}$ insensitivity syndrome (Laron syndrome) treated with recombinant human IGF-I show a modest growth acceleration, but $\mathrm{AH}$ is usually still below the population range. A few reports $[$ e.g $(37,38)]$ suggested that adding a GnRHa may increase $\mathrm{AH}$ if started at the onset of puberty (LoE 4), but controlled studies have not been reported.

\subsection{The Effect of a GnRH Analogue in Combination With Recombinant Human Growth Hormone}

Information on efficacy and safety of GnRHa plus rhGH is available for the following conditions: 1) growth hormone deficiency (GHD); 2) short stature after being born small for gestational age (SGA); 3) ISS; 4) haploinsufficiency of SHOX, NPR2 or ACAN; 5) CPP; 6) congenital adrenal hyperplasia $(\mathrm{CAH})$; and 7) hypothyroidism. For the first two conditions and SHOX haploinsufficiency rhGH treatment is approved in most parts of the world, and for ISS it is registered in the USA and some other countries. For all other conditions reviewed here, the use of rhGH is off label. GnRHa treatment is off-label for all pediatric conditions except CPP.

\subsubsection{GH-Deficient Children}

The most logical group of GH deficient children who may benefit from the addition of a GnRHa are children who develop CPP before or during rhGH treatment, for example children who had undergone treatment of malignancies (39-42) (LoE 2). The recent conference report stated that adding a GnRHa leads to increased $\mathrm{PAH}$ and $\mathrm{AH}$ in such cases (11).

A second class of $\mathrm{GH}$ deficient children in whom comedication with a GnRHa can be considered are those who have not reached full catch-up growth at the onset of puberty (11). Longitudinal data on height in rhGH-treated children with 
GHD have shown that height SDS at the onset of puberty is similar to AH SDS $(43,44)$. This implies that a low height SDS at pubertal onset, even if this is normally timed, likely leads to a low AH SDS. This was the reason that a prospective RCT was carried out in Santiago (Chile) in collaboration with the National Institutes of Health (Bethesda, USA) to compare near-adult height $(\mathrm{NAH})$ of treatment-naïve GHD patients (in Tanner stage II-III, females premenarcheal) treated with either rhGH plus GnRHa (experimental group, $\mathrm{n}=7$ ) or rhGH alone (controls, $\mathrm{n}=10$ ) (45). rhGH was administered until patients reached NAH, and the GnRHa was given for 3 years. BA advancement was significantly different between groups in the 3 year interval $(1.5 \pm$ 0.2 "years" on rhGH plus GnRHa versus $4.2 \pm 0.5$ on $\mathrm{rhGH}$ alone), and NAH was- $1.3 \pm 0.5$ versus $-2.7 \pm 0.3$ SDS, respectively (LoE 1). The difference in NAH was close to $10 \mathrm{~cm}$. While I agree with the authors' conclusion that these results indicate that delaying puberty with a GnRHa in GHD children during treatment with rhGH increases $\mathrm{AH}$, I wish to call the readers' attention to the fact that the patients in this study were quite different from the usual GHD patient in countries where rhGH is approved and reimbursed for this indication. These severely GHdeficient patients entered into the study at a remarkably late mean age of 14.3 years, BA of 11.3 years, height of -4.3 SDS, and PAH of -3.1 SDS. They are therefore not representative for the majority of GHD patients in whom rhGH is typically started within the first decade of life with less severe growth delay.

One year later our group reported on a retrospective analysis of the effect of the addition of GnRHa (started shortly after the onset of puberty) to rhGH treatment in children with GHD and a low height SDS [mean (SD) -3.0 (1.5)] at onset of puberty (43). Matched controls with rhGH treatment only were used for comparison. The children were younger (mean age 8.9 years), equally short at start of rhGH treatment, but less short at the start of GnRHa compared with the subjects in the Chilean RCT (45). The effect of GnRHa addition on $\mathrm{AH}$ [in terms of $\mathrm{AH}$ minus target height $(\mathrm{TH}) \mathrm{SDS}$ ] was estimated at 1.2 SDS (approximately $8.5 \mathrm{~cm}$ ) (LoE 3), so similar to the results of the RCT. We later described an even more impressive height gain of $25-30 \mathrm{~cm}$ as a result of the addition of a GnRHa in two siblings with severe GHD due to a homozygous GHRHR defect who moved to the Netherlands at mid-puberty and started rhGH plus GnRHa treatment at that time (46) (LoE 4).

In the International Consortium's report it was concluded that "the addition of a GnRHa to GH at the onset of puberty and treatment for at least 2 years resulted in gains of $\mathrm{AH}$ ranging from 6 to $9 \mathrm{~cm}(\sim 1-1.5 \mathrm{SD})$ ", in line with my conclusion. This observation is also compatible with the observations in patients with undiagnosed or untreated combined deficiency of GH and gonadotropic hormones, who can reach a normal height or even turn "from dwarfs to giants" $(12,13)$.

Regarding safety of this approach, there is a theoretical risk of decreased bone mineral content (BMC) of 2-3 years of GnRHa. This was investigated in the Chilean RCT (45) and in fact patients treated with rhGH plus GnRHa had a significantly lower BMC after 3 years of therapy. This difference, however, did not persist after both groups of patients reached NAH (47). Another potential adverse event is disproportionate growth (potentially leading to a eunuchoid shape), but this was not observed in the RCT (45). The psychological profiles of the patients who participated in this study showed that their first priority was to increase linear growth, whereas pubertal progression was felt to be of lesser importance, particularly for boys (45).

\subsubsection{Short Children Born Small for Gestational Age}

Pubertal height gain is often less than expected in children born SGA, as a result of an earlier onset of puberty, an earlier peak height velocity, and accelerated bone maturation (11, 48, 49). Therefore, theoretically, it would make sense to add a GnRHa if height SDS is low at pubertal onset in order to increase AH. The results of three studies are in favor of this hypothesis [reviewed in (50)]

First, in a clinical trial on rhGH-treated short early pubertal children born SGA, patients were randomized into 2 groups (rhGH dosage of 1 or $2 \mathrm{mg} / \mathrm{m}^{2}$.day). Children with a height below $140 \mathrm{~cm}$ (-2.5 SDS in the Netherlands) at pubertal onset received GnRHa co-treatment for 2 years, and their growth was compared with that of children with a height above $140 \mathrm{~cm}$ at pubertal onset receiving rhGH only. In children treated with rhGH plus GnRHa, the total height gain on $\mathrm{GH}$ treatment in both dosage groups $(34.5 \mathrm{~cm}$ and girls $24.2 \mathrm{~cm}$ for boys and girls, respectively) was larger than expected for the general population, in spite of a shorter pubertal duration after discontinuation of GnRHa $(51,52)$ (LoE 2). As a result, AH of these rhGH plus GnRHa treated children was similar to $\mathrm{AH}$ of rhGH-treated children who were $>140 \mathrm{~cm}$ at pubertal onset, which would not have been expected without GnRHa co-medication. Extensive studies on this cohort during and up to 5 years after cessation of rhGH regarding body composition, metabolic profile, bone health, cognition, self-perception, behavior and Health-related Quality of Life (HRQoL) showed no adverse effects of the addition of the GnRH analogue (53-57). It is noteworthy that the initially proposed research design (an RCT on the addition of GnRHa) was turned down by the medical ethics committee, because it was expected that adding a GnRHa would have a positive effect on $\mathrm{AH}$.

Second, the combination of rhGH plus GnRHa versus untreated controls for 3 years in short children born SGA or with a normal birth weight (idiopathic short stature, ISS) showed a positive effect on AH in an RCT, but only in girls (58) (LoE 1). Third, a French retrospective study (59) showed that after $4.6 \pm$ 2.8 years of rhGH treatment, height SDS of short children born SGA increased from $-2.2 \pm 0.9$ to $-1.5 \pm 0.9$, and that in a multivariate analysis, the use of a GnRHa therapy for at least 2 years was one of the eight predictive factors (estimated effect 0.4 SD) (59) (LoE 3). The only report suggesting that adding a GnRHa to rhGH treatment had no positive effect on $\mathrm{AH}$ was based on a retrospective analysis (60) of non-standardized GnRHa treatment in 16 of 37 patients with Silver-Russell syndrome (LoE 4) (61).

My interpretation of the available data goes a step further than the one taken by the International Consortium ("it is appropriate to consider the potential advantages and disadvantages of treatment with $\mathrm{GH}$ and $\mathrm{GnRHa}$ in this 
population") and contrasts with a recent opposite view (62). I believe that there is sufficient evidence that co-treatment with a GnRHa for 2-3 years does increase $\mathrm{AH}$ in rhGH treated short SGA-born children if height SDS is $<-2.5$ at pubertal onset.

\subsubsection{Idiopathic Short Stature}

Unlike the previous two conditions, ISS is not an approved indication for rhGH in most parts of the world (except the USA and a few other countries), although reports on post-marketing databases suggest that it has been widely prescribed off label in other countries as well (63). Several studies have been performed on the potential efficacy of the combination of rhGH plus GnRHa in ISS, which can be divided into five sets.

First, there are four reports without follow-up till $\mathrm{AH}$, in which the change in PAH was used as outcome marker for efficacy (64-67). These reports will not further be discussed due to the unavailability of attained $\mathrm{AH}$. The second set contains two uncontrolled studies $(68,69)$. The third set comprises two controlled studies on a short course of rhGH plus GnRHa (58, 70). Set 4 contains two studies comparing the effect of the combination treatment with that of $\mathrm{rhGH}$ alone $(71,72)$. Set 5 is the retrospective Israeli study in prepubertal and pubertal children on the effect of a GnRHa in addition to long-term rhGH treatment (73). Relevant clinical data from the studies in sets 2-5 are presented in Table $\mathbf{1}$.

The two uncontrolled studies in set 2 (LoE 4) presented contradictory results. The Italian study (68) showed no positive effect, while the authors of the Chinese study (69) concluded that GnRHa/rhGH therapy can effectively improve AH SDS up to TH SDS.

Similarly, the results of the two studies in set 3 were contradictory. The small prospective Venezuelan study compared the growth response to rhGH plus GnRHa with that of untreated historical controls (LoE 3) and reported no difference (70). In contrast, the RCT of our group in short children born with a low or normal birth size (58) (LoE 1) showed a mean positive effect on $\mathrm{AH}(5 \mathrm{~cm})$, with a clear difference between sexes: mean (SD) $\mathrm{AH}$ $\mathrm{TH}$ was $-3.3(5.9) \mathrm{cm}$ in the treated group versus $-12.0(5.3) \mathrm{cm}$ in untreated controls $(\mathrm{p}<0.05)$ in girls, compared with $-11.8(6.5)$ versus $-9.7(6.9) \mathrm{cm}$ in boys (NS). It is noteworthy that of the PAH increase of $9.3 \mathrm{~cm}$ between start and discontinuation of treatment, almost 50\% was "lost" between the end of medication and $\mathrm{AH}$. In this study, no long-term negative or positive psychosocial consequences were observed (74), bone mineral density (BMD) did not change significantly, and the effect appeared similar for ISS and SGA (58).

TABLE 1 | Results of studies on the efficacy of rhGH plus GnRHa on adult height in children with idiopathic short stature.

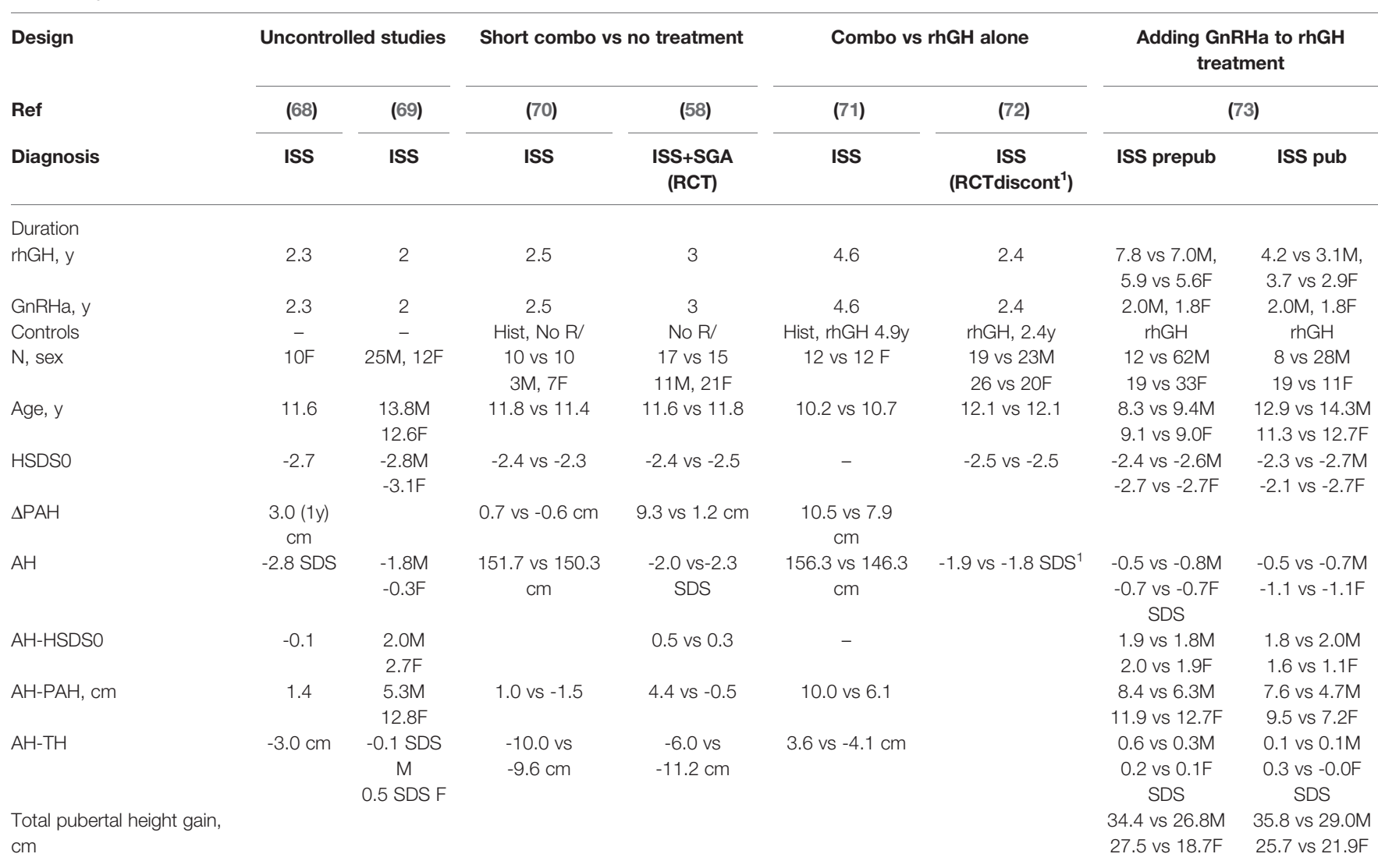

${ }^{1}$ Trial was abrupted after 2.4 years, thus severe loss to follow-up. NAH was reported on a small sample only.

AH, adult height; Combo, combination; discont, discontinued; F, females; HSDSO, height SDS at start of treatment; hist, historical; ISS, idiopathic short stature; M, males; PAH, predicted adult height; R/, treatment; RCT, randomized controlled trial; SGA, small for gestational age; TH, target height; vs, versus; $y$, year. 
In set 4 , the effect of rhGH plus GnRHa for a relatively long period (4.6 years) was compared with that of rhGH-treated matched controls in girls (71). The result was impressive ( $\mathrm{AH}$ $156.3 \pm 5.9$ vs. $146.3 \pm 5.0 \mathrm{~cm}$, so $10 \mathrm{~cm}$ difference). The large RCT comparing the combination treatment with rhGH alone (72) was unfortunately aborted at the request of the French regulatory authorities ( $\operatorname{LoE} 2$ ). NAH was only reported on 35 of the included 91 children, which did not show a difference between treatment regimens. Bone fractures occurred more frequently in the $\mathrm{GH}$ plus leuprorelin group than in the $\mathrm{GH}$ alone group (seven versus 3, respectively), but no bone fractures were reported during the safety follow-up period.

Finally (set 5), the effect of adding GnRHa in puberty was investigated in a retrospective analysis on 58 out of 192 children who either started rhGH treatment before $(n=31)$ or during puberty $(n=27)(73)$. The authors concluded that combined rhGH/GnRHa therapy increased AH outcome, and that this effect was more pronounced in the prepubertal group and in girls. The mean effect on total pubertal growth was $8-9 \mathrm{~cm}$ (LoE 3).

Though strictly speaking short, adopted girls should not be labeled ISS, I also mention in this paragraph two studies on adopted girls showing an estimated mean height gain of 3-4 cm on rhGH plus GnRHa versus GnRHa alone (LoE 1) $(75,76)$.

The general picture arising from these studies is that in countries where rhGH can be prescribed for children with ISS, clinicians can consider adding a GnRHa if puberty starts when height SDS is still below the reference range at onset of puberty, particularly in girls $(58,71,73)$. A longer duration of GnRHa comedication than 3 years may have a larger effect on $\mathrm{AH}$ (71), but its potentially negative psychosocial consequences should be considered as well.

\subsubsection{Haploinsufficiency of SHOX, NPR2, or ACAN}

In children with haploinsufficiency of SHOX, NPR2 or ACAN, the prepubertal growth rate is relatively well-preserved but followed by a compromised pubertal growth spurt due to premature growth plate fusion, so that height SDS decreases by age (77-79). SHOX haploinsufficiency is a registered indication for rhGH since 2006 (80), but this does not apply to the two other genetic syndromes. The few anecdotal reports on the administration of GnRHas as co-treatment to $\mathrm{rhGH}$ in children with these genetic defects are reviewed in the next paragraphs.

\subsubsection{SHOX Haploinsufficiency}

In a retrospective analysis of 10 children with $S H O X$ haploinsufficiency (77), five patients were followed without treatment, and five were treated with $\mathrm{rhGH}(50 \mu \mathrm{g} / \mathrm{kg} . \mathrm{d})$ plus GnRHa. Mean AH SDS minus height SDS at first evaluation was significantly different between treated $(+0.6)$ versus nontreated $(-1.2)$ patients (77) (LoE 4), but obviously the relative contribution of the two components of this combined therapy is unknown. In a Japanese paper two girls with SHOX haploinsufficiency were treated with rhGH and a few years of GnRHa, but the reported data do not allow for assessing the contribution of GnRHa co-treatment (81) (LoE 4).

\subsubsection{NPR2 Haploinsufficiency}

In a recent paper the data of 21 patients with heterozygous NPR2 variants who were treated with rhGH were summarized. In three of them a GnRHa was added and in one case letrozole (82). The first reported case (83) was treated with a GnRHa for 1.5 years from 13.3 years onward and with $\mathrm{rhGH}(33 \mu \mathrm{g} / \mathrm{kg}$.d $)$ for 3.3 years from the age of 13.8 years. Height SDS increased from -2.8 to -2.5 SDS and AH was $158 \mathrm{~cm}$, similar to the heights of his affected father and grandfather, suggesting no beneficial effect (LoE 4).

In the same paper (83), the results were reported of treatment of rhGH $(50 \mu \mathrm{g} / \mathrm{kg} . \mathrm{d})$ plus GnRHa in a 12.8 year old boy. Puberty had started at 12.1 years, when he was $131 \mathrm{~cm}$ and had a PAH of $160 \mathrm{~cm}$. After 2.7 years of treatment, GnRHa was discontinued. $\mathrm{He}$ reached an $\mathrm{AH}$ of $164 \mathrm{~cm}$, suggestive for an $\mathrm{AH}$ gain of $4 \mathrm{~cm}$ (LoE 4).

Growth data of the third case (84), showed that treatment with rhGH for 11.6 years and an unreported duration of GnRHa led to a height SDS increase from -3.8 to -3.1 SDS (82) (LoE 4). Taken together, rhGH plus GnRHa appears to have a modest $\mathrm{AH}$-augmenting effect, but the respective roles of rhGH and GnRHa cannot be assessed in this condition.

\subsubsection{ACAN Haploinsufficiency}

Approximately $50 \%$ of children with ACAN haploinsufficiency present with an accelerated BA (85) and mean height SDS decreases by age (79), so clinicians have been tempted to investigate the potential role of rhGH plus GnRHa to increase $\mathrm{AH}$. In a large international patient series, five children received rhGH plus GnRHa, which indeed appeared to halt skeletal maturation (79) (LoE 4). In a recent report on 6 novel cases with heterozygous $A C A N$ variants, the authors reviewed previously published cases who were treated with rhGH with $(n=11)$ and without $(n=10)$ a GnRHa or an AI (86) (LoE 4). Unfortunately, no separate analysis was made for GnRHs and AIs. No statistically significant differences were found in terms of $\mathrm{AH}$, but the presumably wide interindividual differences in age at start of medication and other relevant clinical variables make it difficult to interpret these findings. Specifically in patients with $A C A N$ haploinsufficiency, accelerated epiphyseal fusion during pubertal years remains a worrisome clinical problem and studies investigating add-on GnRHa or AI therapy in these patients should be a priority.

\subsubsection{Central Precocious Puberty Associated With a Persistently Low Predicted Adult Height}

While in most cases of CPP treatment with a GnRHa leads to an increase of PAH and a normal AH (10), there are patients with $\mathrm{CPP}$ in whom PAH remains low on GnRHa alone, usually associated with a very low height velocity. The addition of rhGH to GnRHa treatment in 10 girls for 2-3 years led to an $\mathrm{AH}$ gain of $7.9 \mathrm{~cm}$ in comparison to $1.6 \mathrm{~cm}$ with $\mathrm{GnRHa}$ alone in matched controls (87) (LoE 3). Longer follow-up in a larger cohort showed a mean additional AH gain of $6 \mathrm{~cm}$ (88) (LoE 3). Of note, rhGH has not been registered for this indication by any of the drug regulatory agencies.

An observational study on rhGH plus GnRHa showed that this treatment was associated with a height gain of $5.4 \mathrm{~cm}$ in 18 
girls with CPP, compared to $3.0 \mathrm{~cm}$ in 62 girls receiving the same treatment but with normal onset of puberty (42) (LoE 4).

A meta-analysis of controlled studies in CPP with severely decreased growth velocity during GnRHa therapy (89) reported an increased $\mathrm{AH}$ in patients with GnRHa plus rhGH versus GnRHa alone [ $+2.8 \mathrm{~cm}$ in four clinical controlled trials (CCTs) and $+4.3 \mathrm{~cm}$ in one RCT], as well as greater $\mathrm{AH}-\mathrm{TH}(+3.9 \mathrm{~cm}$ in the CCTs and $+4.0 \mathrm{~cm}$ in the RCT) and greater AH-PAH $(+3.5$ $\mathrm{cm}$ in the CCTs and $+3.9 \mathrm{~cm}$ in the RCT). Patients with a low growth velocity or no improvement in $\mathrm{PAH}$ during $\mathrm{GnRHa}$ benefitted most from the combination therapy (89) (LoE 2). A systematic review and meta-analysis reported an increase of $\mathrm{PAH}$ of $6.5 \mathrm{~cm}$ in CPP when treated with rhGH plus GnRHa, especially in those starting treatment before 10 years old, or with treatment lasting more than 12 months (90). Compared to GnRHa alone, the combined treatment showed a $3.7 \mathrm{~cm}$ higher PAH (LoE2). AH was not reported.

In a large retrospective analysis on girls with CPP or early and rapidly progressive puberty (91), the effect on $\mathrm{AH}$ of GnRHa plus rhGH treatment, GnRHa alone, or no treatment were compared. Compared to no treatment, GnRHa alone yielded an $\mathrm{AH}$ gain of $1.5 \mathrm{~cm}$ and when combined with rhGH an additional $1.5 \mathrm{~cm}$ was gained. Compared to TH, GnRHa alone showed an increase of $2.0 \mathrm{~cm}$ and combined with rhGH a total increase of $4.0 \mathrm{~cm}$, while controls reached their average TH. An AH-PAH of at least $+5 \mathrm{~cm}$ was reached in $60 \%$ of controls, $70 \%$ of GnRHa and $75 \%$ of those with combination therapy, especially those with a more advanced $\mathrm{BA}$ and low PAH. Lower percentages were seen when the $\mathrm{TH}$ $\mathrm{AH}$ endpoint was used $(10 \%, 25 \%$ and $45 \%$, respectively) (LoE 3).

\subsubsection{Congenital Adrenal Hyperplasia}

In general, growth of children treated for $\mathrm{CAH}$ stays within the population range if glucocorticoid dosage is minimized (to avoid iatrogenic Cushing's syndrome), mineralocorticoids are properly dosed and supplemental sodium is given to infants (92). The Endocrine Society Clinical Practice Guideline recommended against routine use of experimental therapies to promote growth and delay puberty (92). However, several retrospective studies showed that mean $\mathrm{AH}$ of children treated for $\mathrm{CAH}$ is approximately 1 SD below the population mean, probably due to a combination of the condition itself and its treatment (93).

Several groups have tried to increase AH by adding rhGH plus GnRHa (both off-label for this indication) to the conventional treatment with hydrocortisone and fludrocortisone acetate. In a study comparing 2 years of rhGH alone or rhGH plus GnRHa cotreatment versus controls without such treatment, mean $\mathrm{PAH}$ increased by $11 \mathrm{~cm}$ in both experimental groups combined and closely approximated $\mathrm{TH}$, while $\mathrm{PAH}$ did not change in controls. There was no difference between the groups treated with rhGH alone and those treated with the combination of rhGH with GnRHa (94) (LoE 3).

In another study, rhGH plus GnRHa therapy was given for 4.2-4.4 years and results were compared with matched controls. In the treatment group, AH SDS was 1 SD greater than both the initial PAH SDS and AH SDS of the untreated group (95) (LoE 3). Six years later, in a nonrandomized prospective study, the same group reported 34 patients that were predicted to be more than 2 SD below $\mathrm{TH}$ or the population mean at around 8 years old, treated with either rhGH alone $(n=7)$ or combined with $\mathrm{GnRHa}$ in case of precocious or early puberty $(\mathrm{n}=27)$. AH was $9.2 \pm 6.7 \mathrm{~cm}$ higher than initial PAH in males, and $10.5 \pm 3.7 \mathrm{~cm}$ in females (96) (LoE 3). There were no differences between the two treatment options, although the rhGH alone group started treatment at a later age. In subjects with poor adrenal control (all males), the gain was only $4.0 \pm 3.0 \mathrm{~cm}$.

In a retrospective analysis (97), 13 patients were treated with rhGH plus GnRHa. rhGH was given for 1.0-6.3 years and GnRHa for 2.1.-6.2 years. On average, an increase of 2 SD in height SDS for BA was noted in the first years after treatment, which remained stable until NAH was reached (LoE 3). In another study (98), 32 CAH patients with CPP were treated with GnRHa $(n=11)$, GnRHa plus letrozole $(n=11)$, or no additional treatment $(n=10)$. Compared to no additional treatment, only the GnRHa plus letrozole group had a higher NAH (-1.3 vs -2.5 SDS) (LoE 3). A Chinese retrospective study compared the effect of two regimens: rhGH plus GnRHa and rhGH plus GnRHa plus letrozole (for an average period of 25 months). PAH increased by $9 \mathrm{~cm}$ versus $12 \mathrm{~cm}$, respectively (99) (LoE 3).

From the available data I conclude that in the subset of $\mathrm{CAH}$ patients with a low $\mathrm{PAH}$ at pubertal onset, adding rhGH alone or in combination with a GnRHa may increase $\mathrm{AH}$.

\subsubsection{Hypothyroidism}

In a case-report two patients with severe acquired juvenile hypothyroidism presenting with compromised $\mathrm{PAH}$ were treated with rhGH plus GnRHa in addition to LT4 (100). In the first patient, a 13 year-old girl, $\mathrm{PAH}$ decreased to $144 \mathrm{~cm}$ after one year of LT4 treatment. rhGH plus GnRHa for one year slowed BA progression, and led to an $\mathrm{AH}$ of $155 \mathrm{~cm}$ (LoE 4). In the second patient, a 14 year-old boy, a 2 year treatment with rhGH plus GnRHa was initiated in addition to LT4 leading to improvement of growth velocity $(10.6 \mathrm{~cm} / \mathrm{yr})$ while slowing bone age progression, resulting in an $\mathrm{AH}$ equal to $\mathrm{TH}$, an increase of $10 \mathrm{~cm}$ compared with PAH after one year of LT4 treatment (LoE 4 ). When one compares these observations with the study on the effect of the addition of GnRHa alone (36) (paragraph 2.1.1), the addition of rhGH appears crucial for a substantial height gain, but obviously observations in two patients are insufficient for a reliable assessment.

\subsection{Safety of GnRHas in Childhood and Adolescence}

According to the GnRHa consensus meeting (10), "GnRHas are generally well tolerated in children and adolescents. Systemic complaints such as headaches or hot flashes occur occasionally but are usually short-term and do not interfere with therapy. Local adverse events occur in $10-15 \%$ patients and necessitate a change in agent when persistent, because they can result in sterile abscesses in a fraction of the patients. Although exceedingly rare, anaphylaxis has been described". The International Consortium gave a very elaborate description of possible adverse events, but basically the conclusion was the same: "Adverse effects of GnRHa 
therapy are rare, and the associations of most reported adverse events with the GnRHa molecule itself are unclear. Decades of experience have shown that GnRHa treatment is both safe and efficacious" (11). In a few studies negative effects on bone acquisition have been reported $(27,45,58)$, but these appear transient (47).

The main downside of GnRHa treatment is that it brings the early- or mid-pubertal adolescent back to a prepubertal state, not suitable to his or her age, which may lead to psychosocial issues and differences in behavior and interests compared with peers.

\section{THE EFFECT OF AROMATASE INHIBITORS}

While GnRHas can be considered as having a "semi-physiologic" effect (by bringing the body back to a prepubertal state), AIs are clearly pharmacological agents. They are registered for the treatment of estrogen-dependent breast cancer, and aimed at decreasing the exposure to estrogens as much as possible, primarily by inhibiting the intracellular conversion of androgens to estrogens, but also by decreasing circulating estrogen concentrations. At present, there are three so-called third generation AI compounds registered: letrozole $(2.5 \mathrm{mg}$ o.d.), anastrozole ( $1 \mathrm{mg}$ o.d.) and exemestane ( $25 \mathrm{mg}$ o.d.). The effect of letrozole on aromatase inhibition is stronger compared to that of anastrozole [ $88 \%$ vs $85 \%$ tissue aromatase blockade in postmenopausal women (101)], with mean residual estradiol concentrations of $10.1 \%$ for anastrozole and $5.9 \%$ for letrozole (102), consistent with observations in boys with ISS (103). Exemestane is a nonsteroidal aromatase inhibitor, and covalent binding of the drug to the active site of the enzyme irreversibly inhibits aromatase action, in contrast to the two non-steroidal AIs which form a reversible bond with the enzyme [reviewed in (5)].

AIs are not registered for any pediatric indication and as far as I know no basic pharmacological studies have been performed in children or adolescents. Therefore, no information is available on the optimal dosages for the three compounds if they would be used in childhood and adolescence. In fact, in pediatric studies the same dosage has been used as for adults, which probably leads to maximum suppression of aromatase. The use of AIs has been investigated in four groups of conditions: hyperestrogenism, hyperandrogenism, pubertal gynecomastia, and short stature and/or delayed puberty (5).

\subsection{Use of Aromatase Inhibitors in Hyperestrogenism, Hyperandrogenism, or Pubertal Gynecomastia}

Four rare disorders characterized by hyperestrogenism (aromatase excess syndrome, Peutz-Jeghers syndrome, McCune-Albright syndrome, and functional follicular ovarian cysts) are logical indications for AIs. For details I refer to a previous review (5) and a recent paper on Peutz-Jeghers syndrome (104).
Regarding hyperandrogenism, the efficacy of AIs in testotoxicosis, also known as familial male-limited precocious puberty, is well established (5). The positive effect of long-term treatment with the combination of an antiandrogen, aromatase inhibitor and GnRH analogue was recently confirmed $(105,106)$ (LoE 2).

As mentioned in paragraph 2.2.6, the conventional treatment of children with 21-hydroxylase deficiency with a combination of hydrocortisone and fludrocortisone acetate may in some children lead to a low AH. A lower dosage of corticosteroid treatment in combination with a first generation $\mathrm{AI}$ and an androgen antagonist appeared efficacious (107), but became outdated by the arrival of second and third generation AIs.

The addition of letrozole to $\mathrm{CAH}$ patients with concomitant CPP who received a GnRHa led to a significantly higher NAH compared with the no intervention group (98) (LoE 3). In a recent case report the effect of 9 years of exemestane, combined with 4 years of GnRHa treatment because of early central puberty, was described in a patient with markedly advanced BA (108) (LoE 4). At start of exemestane the PAH was -4.6 SDS and at its discontinuation NAH was -0.8 SDS. In another study, already mentioned in paragraph 2.2.6, the addition of letrozole to rhGH plus GnRHa had an additional effect of $3 \mathrm{~cm}$ (99) (LoE 4).

Also patients with an $11 \beta$-hydroxylase deficiency can end up short, particularly if the diagnosis is made during later childhood. The first report on 11 years of administration of letrozole without $\mathrm{rhGH}$ in a boy with $11 \beta$-hydroxylase deficiency demonstrated a $35 \mathrm{~cm}$ increase in AH over PAH (109) (LoE 4). This was combined with a GnRH analogue for 2.5 years due to central activation of puberty. However, significant adverse events were reported in this patient: back pain and vertebral changes were noted from the age of 15 years onwards, as well as impaired sperm motility and subnormal morphology. Two case reports showed that the addition of rhGH and an AI to glucocorticoid replacement was highly efficacious (LoE 4). The first case (110) was treated with rhGH and letrozole resulting in a higher $\mathrm{AH}$ as compared with PAH. The second case (111), treated with rhGH plus anastrozole, reached an $\mathrm{AH}$ of $11.5 \mathrm{~cm}$ above $\mathrm{TH}$. In these patients no side effects were noted.

While initially AI treatment appeared to be a rational approach in boys with pubertal gynecomastia, the results have been disappointing (5). In a recent clinical practice guideline the use of selective estrogen receptor modulators, aromatase inhibitors, or non-aromatizable androgens was not recommended for this self-limiting condition (112).

\subsection{Use of Aromatase Inhibitors in Boys With Short Stature and/or Delayed Puberty}

Third generation AIs have been used as a potential agent to enhance $\mathrm{AH}$, particularly letrozole ( $2.5 \mathrm{mg}$ o.d.) and anastrozole (1 mg o.d.). The motivation to initiate such studies was the observation that males with a pathogenic variant of the genes encoding the estrogen receptor or aromatase show a substantial BA retardation while their stature in childhood and adolescence was normal, resulting in increased $\mathrm{AH}(14,15,113-116)$. 
Regarding the use of AIs in children, there is one systematic review by the Cochrane group (117), which concluded that the "available evidence suggested that aromatase inhibitors improved short-term growth outcomes", but that "there was no evidence to support an increase in $\mathrm{AH}$, based on limited data, with only one of four trials publishing $\mathrm{AH}$ data under nonrandomized conditions" (LoE 2).

In most reports and reviews on AIs, the authors apparently assumed that the effects of letrozole and anastrozole are similar regarding growth and skeletal maturation. In contrast, I believe that there is circumstantial evidence that the effects differ to some extent, which may well be related to the different degree of blocking aromatase. The biphasic dose-response relationship of estrogens and growth discussed in paragraph 1 would suggest that a total blockade of estrogen exposure may have a negative effect on growth, which could serve as an argument in favor of anastrozole above letrozole.

Unfortunately, there is little information about a direct comparison between the efficacy and safety of both compounds in childhood. There is only one study in which the effect was studied on growth and BA in short pubertal males. First year height velocities were similar, but PAH increased more in the anastrozole group (118) (LoE 3). The study in which either letrozole or anastrozole was administered to boys with ISS (103) was not powered to detect differences between the effect of these drugs on growth and skeletal maturation. Similarly, there is no direct comparative information about adverse events in adolescents of both compounds, but the published data seem to suggest that adverse events are seen more frequently on letrozole treatment than on anastrozole.

In the following paragraphs I summarize the outcome of clinical studies in children/adolescents at risk of a low $\mathrm{AH}$, as a follow-up to several previous reviews $(1,3,5,119-122)$.

\subsubsection{Idiopathic Short Stature, Growth Hormone Deficiency, and Constitutional Delay of Growth and Puberty}

Several studies have been performed with AIs in boys with ISS, constitutional delay of growth and puberty (CDGP) (which I consider equivalent to ISS with delayed onset of puberty) or GHD (5). Auxological data from several studies are presented in Tables 2, 3. Given the possible differences in efficacy and safety between letrozole and anastrozole, the results will be discussed in separate paragraphs for studies on letrozole, anastrozole and studies in which both were used.

\subsubsection{Letrozole}

The first RCT on the effect of letrozole in boys with CDGP (128, 129) appeared to lead to a small gain of NAH (LoE 1), but as discussed previously (5) there are several issues which make this claim uncertain. The most important issue is potential selection bias at start of treatment and in the final analysis. Further, results obtained with a combination treatment (letrozole plus testosterone) cannot be extrapolated to letrozole alone. In addition, no $\mathrm{AH}$ data were reported for the untreated boys, and the attained $\mathrm{AH}$ might be considerably higher than the NAH, since the range of bone ages at follow-up was quite wide (15.8-18.0 years).
The same Finnish group also performed an RCT on the effect of a 2 year course of letrozole vs. placebo in peripubertal boys with ISS (prepubertal in 90\%) (Table 2). At discontinuation of medication there was a $5.9 \mathrm{~cm}$ increase of $\mathrm{PAH}$ on letrozole (123), but the authors have to be praised for performing a study on attained $\mathrm{AH}$. This showed that there was no statistically significant difference in $\mathrm{AH}$ (124) (LoE 1). Of note, in both groups, the attained $\mathrm{AH}$ was $3 \mathrm{~cm}$ lower than $\mathrm{PAH}$ at start of treatment (124). Regarding the study design, in hindsight, it would have been more logical to start letrozole in early- or midpuberty than before puberty. Minor vertebral deformities occurred in boys who were prepubertal at start (130), but this ameliorated with time (124). The results of this study serve as a warning against overestimating the accuracy of PAH calculations after a therapeutic course with a puberty modulator.

In an Iranian study, 91 boys with CDGP were randomly allocated to letrozole, placebo or oxandrolone for 2 years (131). The results showed several questionable issues (5) and unfortunately we have been unable to obtain clarifications from the authors (LoE 4). In another Iranian study (132) the effect of one year on letrozole versus no treatment in small groups of 6 boys was reported. The authors concluded that letrozole treatment was associated with an $\mathrm{AH}$ of $1.9 \mathrm{~cm}$ above $\mathrm{PAH}$, in contrast to no increase in controls $(0.1 \mathrm{~cm})$. However, the letrozole group was investigated at a considerably older age than the controls (23.4 versus 19.9 years) (LoE 3).

In a retrospective chart review of 21 boys with predicted short stature and/or rapidly advancing BA, due to many different diagnoses, 19 received letrozole, one subject anastrozole, and one subject initially anastrozole for 1 year followed by a switch to letrozole. No increase of PAH was observed, regardless of Tanner stage (2) (LoE 4).

Finally, a recent Finnish randomized controlled phase 3 trial tested whether letrozole for 6 months might be a feasible alternative treatment to low-dose testosterone for boys with CDGP (133). Thus, this study was not aimed at investigating whether letrozole would result in a taller $\mathrm{AH}$. In the letrozole group serum concentrations of LH, FSH, testosterone and inhibin-B as well as testicular volume were higher than in the testosterone group, but height velocity was slightly lower ( $\mathrm{LoE} 1$ ). The safety profile of both regimens was satisfactory, but the authors warned that "the risks and benefits of manipulating the reproductive axis during early puberty should be weighed carefully" (133).

A case report of a $\mathrm{GH}$ deficient boy who received letrozole for 17 month in addition to rhGH suggested a positive effect on $\mathrm{PAH}$, but unfortunately no data on attained $\mathrm{AH}$ were reported (134) (LoE 4). Another case report on the effect of 5 years of letrozole in a 14.5-year-old boy with ISS demonstrated that $\mathrm{AH}$ surpassed the pre-treatment PAH by $15 \mathrm{~cm}$ (135) (LoE 4).

\subsubsection{Anastrozole}

In an RCT from the USA, 52 adolescent males with GH deficiency treated with rhGH were randomized to cotreatment with anastrozole or placebo daily for up to 36 months. Anastrozole cotreatment was associated with slower bone maturation and higher $\mathrm{PAH}$ while maintaining normal pubertal progression after 2-3 yr (125) (LoE 1) (Table 3). 
TABLE 2 | Effect of letrozole (Let) or anastrozole (Ana) on growth in boys with idiopathic short stature (ISS).

\begin{tabular}{|c|c|c|c|c|c|c|c|}
\hline \multirow{3}{*}{$\begin{array}{l}\text { Country, Diagnosis (duration) } \\
\text { Reference } \\
\text { Medication }\end{array}$} & \multirow{2}{*}{\multicolumn{2}{|c|}{$\begin{array}{c}\text { Finland, ISS ( } 2 \text { yrs) } \\
(123,124)\end{array}$}} & \multirow{2}{*}{\multicolumn{2}{|c|}{$\begin{array}{c}\text { US, ISS, } 1 \text { yr } \\
(118)\end{array}$}} & \multirow{2}{*}{\multicolumn{3}{|c|}{$\begin{array}{c}\text { US, ISS, } 2 \text { yrs } \\
(103)^{\star}\end{array}$}} \\
\hline & & & & & & & \\
\hline & Let & Placebo & Let & Ana & Let/Ana & GH & Let/Ana+GH \\
\hline $\mathrm{N}$ & 10 & 10 & 17 & 22 & 25 & 25 & 26 \\
\hline \multicolumn{8}{|l|}{ At start } \\
\hline Age, yrs & $11.5(1.8)$ & $10.9(1.8)$ & $14.1(1.3)$ & $14.1(1.4)$ & 14.2 (0.2 & $14.1(0.2)$ & $14.0(0.2)$ \\
\hline $\mathrm{Hgt}, \mathrm{cm}$ & $129.7(7.9)$ & $127.5(7.5)$ & $148.7(6.2)$ & $149.3(6.7)$ & $145.7(1.1)$ & $144.2(1.4)$ & 144.5 (1.3) \\
\hline Hgt SDS & $-2.4(0.3)$ & $-2.5(0.4)$ & & & $-2.2(0.1)$ & $-2.4(0.1)$ & $-2.3(0.1)$ \\
\hline $\mathrm{HV}, \mathrm{cm} / \mathrm{yr}$ & & & 7.1 (3.0) & $6.0(3.5)$ & & & \\
\hline $\mathrm{TH}, \mathrm{cm}$ & & & $175.3(4.5)$ & $173.8(8.7)$ & $171.8(0.8)$ & $170.1(1.3)$ & $171.6(0.9)$ \\
\hline BA, yrs & $9.2(2.6)$ & $8.7(1.9)$ & $13.3(0.7)$ & $13.4(0.8)$ & $12.8(0.3)$ & $12.9(0.3)$ & $12.7(0.2)$ \\
\hline $\mathrm{PAH}, \mathrm{cm}$ & $167.6(7.9)$ & 166.9 (3.9) & $166.4(4.5)$ & $165.7(5.2)$ & & & \\
\hline Testic vol, ml & $1.5(1.4)$ & $1.0(0.6)$ & $8.3(3.2)$ & 7.7 (3.5) & & & \\
\hline Tanner G & 8/2/0/0/0 & 10/0/0/0/0 & 0/8/8/1/0 & 0/9/9/4/0 & 2-3 & 2-3 & 2-3 \\
\hline $\mathrm{T}, \mathrm{nmol} / \mathrm{L}$ & $1.4(1.9)$ & $0.4(0.4)$ & & & $7.1(1.3)$ & $8.5(1.4)$ & 7.7 (1.3) \\
\hline \multicolumn{8}{|l|}{ At stop } \\
\hline Age & & & $15.2(1.3)$ & $15.2(1.5)$ & & & \\
\hline Hgt, cm & & & $156.4(5.1)$ & $157.6(6.7)$ & & & \\
\hline Hgt SDS & & & & & $-1.73(0.1)$ & $-1.43(0.1)$ & $-1.25(0.1)$ \\
\hline $\mathrm{HV}, \mathrm{cm} / \mathrm{yr}$ & & & $7.2(2.1)$ & $7.2(1.8)$ & & & \\
\hline$\Delta$ hgt,cm & & & & & 14. (0.8) & $17.1(0.9)$ & $18.9(0.8)$ \\
\hline BA, yrs & $10.2(2.9)$ & $10.8(1.5)$ & $14.2(0.8)$ & $14.2(0.9)$ & & & \\
\hline$\Delta \mathrm{BA}, \mathrm{yrs}$ & 1.24\# & 2.05\# & & & $2.1(0.3)$ & $2.5(0.1)$ & $1.9(0.2)$ \\
\hline $\mathrm{PAH}, \mathrm{cm}$ & 174.0 (8.3) & $167.4(4.3)$ & 167.7 (5.6) & 169.9 (6.3) & & & \\
\hline HSDSBA & & & & & $-1.06(0.1)$ & $-1.11(0.2)$ & $-0.41(01)$ \\
\hline$\triangle \mathrm{PAH}, \mathrm{cm}$ & $6.4(2.2)$ & $0.5(4.4)$ & $1.4(4.4)$ & $4.4(3.5)$ & & & \\
\hline Testic vol, ml & & & $14.3(3.3)$ & $14.0(2.7)$ & & & \\
\hline Tanner G & $5 / 0 / 1 / 1 / 3$ & $3 / 3 / 2 / 2 / 0$ & $0 / 0 / 4 / 12 / 1$ & 0/1/7/10/3 & $4-5$ & & \\
\hline \multicolumn{8}{|l|}{ At (near-)AH } \\
\hline Age & $23.3(4.0)$ & $21.7(3.1)$ & & & $17.4(0.2)$ & & \\
\hline Hgt, cm & $164.8(4.0)$ & $163.7(3.7)$ & & & $164.1(1.6)$ & $164.8(1.6)$ & $166.9(1.5)$ \\
\hline $\mathrm{NAH}-\mathrm{TH}$ & & & & & $-7.8(1.6)$ & $-5.3(1.3)$ & $-4.5(1.4)$ \\
\hline$\Delta \mathrm{Hgt}, \mathrm{cm}$ & & & & & $18.2(1.6)$ & $20.6(1.5)$ & $22.5(1.4)$ \\
\hline$\Delta \mathrm{Hgt} 3 y r s$ & & & & & $23.8(2.3)$ & 26.7 (2.0) & 30.7 (1.1) \\
\hline$\Delta$ Hgt 2yrs & & & & & $14.7(1.5)$ & $17.8(1.6)$ & $19.9(1.4)$ \\
\hline Hgt SDS & $-2.6(0.7)$ & $-2.7(0.7)$ & & & $-1.4(0.1)$ & $-1.4(0.2)$ & $-1.0(0.1)$ \\
\hline $\mathrm{BA}, \mathrm{yrs}$ & $18.5(0.7)$ & $18.7(0.7)$ & & & $15.3(0.1)$ & & \\
\hline Testic vol, ml & $12.8(3.0)$ & $12.2(3.5)$ & & & & & \\
\hline
\end{tabular}

*Data from Mauras et al. are expressed as mean (SE). Data from other papers are expressed as mean (SD).

"Derived from Hero et al, 2005 on 16 and 14 patients, respectively.

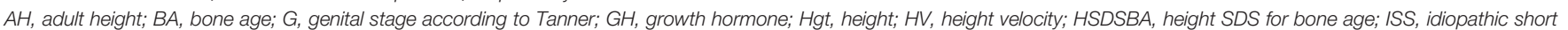
stature; NAH, near-adult height; PAH, predicted adult height; SDS, standard deviation score; T, testosterone; testic, testicular; TH, target height; vol, volume; yrs, years.

Unfortunately, no AH data could be collected. Furthermore, the interpretation of the results is complicated because of a potential selection bias, since the number of patients who could be analyzed decreased from the original 52 to 41 and 28 completing 2 and 3 years, respectively, without information on the distribution per group.

An interesting approach was taken by a French group (126), which explored the effect on $\mathrm{AH}$ of rhGH plus anastrozole, compared with rhGH alone and historical untreated controls, by the end of puberty in boys with ISS (Table 3). In this small study, rhGH plus anastrozole, despite being started at such late stage of puberty, seemed to allow boys with ISS to reach a greater $\mathrm{AH}$ than rhGH alone (LoE 2).

\subsubsection{Letrozole or Anastrozole}

As mentioned previously, first year data from a direct comparison of anastrozole and letrozole in children with ISS confirmed that letrozole is more potent in hormonal manipulation, but suggested that $\mathrm{PAH}$ increased more in the anastrozole group (118) (LoE 3). Unfortunately, long-term results of this study have not been reported, but even if these would be available, the lack of an untreated control group would have hampered the interpretation.

An RCT in 76 boys with ISS consisted of three arms: 1) AI (letrozole or anastrozole); 2) rhGH, and; 3) AI plus rhGH (103). The authors concluded that AI plus rhGH for 24-36 months increased height potential in pubertal boys with ISS more than rhGH or AI alone (LoE 1), but unfortunately no data have been reported on attained $\mathrm{AH}$. The effect was considerably greater if patients were treated for at least 36 months, but this could only be investigated in the 19 out of 54 boys with a residual height potential at 24 months who chose to continue treatment, resulting in potentially selective loss to follow up. As mentioned earlier, the study was not powered to investigate 
TABLE 3 | Effect of anastrozole (Ana) or letrozole (Let) in boys with growth hormone deficiency (GHD) or idiopathic short stature (ISS).

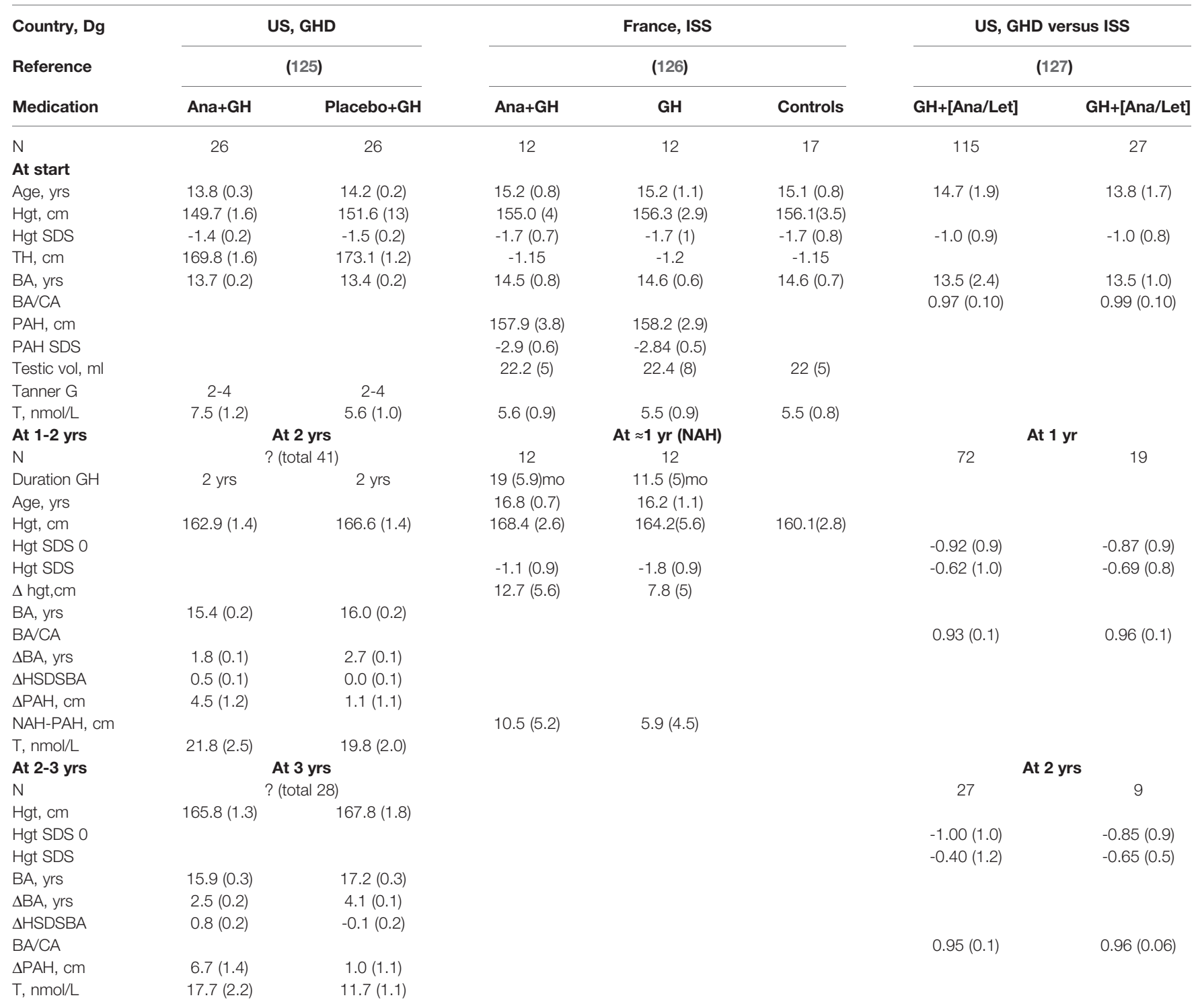

BA, bone age; CA, chronological age; G, genital stage according to Tanner; Hgt, height; Hgt SDS o, height SDS at baseline; HSDSBA, height SDS for bone age; mo, months; NAH, nearadult height; PAH, predicted adult height; SDS, standard deviation score; T, testosterone; testic, testicular; TH, target height; vol, volume; yrs, years.

differences between letrozole and anastrozole in terms of efficacy and safety. The total QoL scores increased significantly at 24 months in the rhGH and AI plus rhGH group, but QoL derived from the children's reports did not increase in the AI group, while it increased in all groups in the parents' reports. Increases in QoL scores were associated with increases in height SDS (136).

A retrospective assessment of the effect of anastrozole or letrozole with or without rhGH treatment for a mean period of 2.1 years was performed in 96 adolescent boys with, as stated in the report, an "idiopathic decrease in PAH when compared with TH" (137). In contrast, the baseline data showed that mean pretreatment PAH was close to mean $\mathrm{TH}$ (range -3.4 to $+2.4 \mathrm{~cm}$ around $\mathrm{TH}$ ) and mean height SDS ranged between -1.0 and 0.0 . The normal stature of these boys and low number of patients who reached NAH $(n=22)$, as well as the retrospective design, preclude firm conclusions (LoE 4).

In an observational study from the United States (127) on boys with GHD or ISS, with a similar loss to follow up and risk of selection bias as mentioned for the RCTs, the authors concluded that the addition of an AI may augment growth potential as indicated by continued height SDS increase with decreased BA/ chronological age (BA/CA) ratio (Table 3) (LoE 4).

A recent study from China reported on a comparison of the effect of rhGH alone or combined with letrozole or anastrozole for one year or more (138). After intervention, there were significant differences in $\triangle \mathrm{BA} / \Delta \mathrm{CA}, \Delta \mathrm{Height} \mathrm{SDS}$ for $\mathrm{BA}$ and $\triangle \mathrm{PAH}$ between the rhGH plus AI group and the rhGH group (LoE 3). However, multiple adverse events were reported (see later). 


\subsubsection{Haploinsufficiency of SHOX, NPR2, and ACAN}

There are only a few anecdotal reported data on the combination of rhGH plus AI in children with these genetic variants. One child with a heterozygous pathogenic NPR2 variant was treated with $\mathrm{rhGH}$ in a dosage of $50 \mu \mathrm{g} / \mathrm{kg} . \mathrm{d}$ and letrozole $(2.5 \mathrm{mg} / \mathrm{d})$ since he was 13 years old (83). His height SDS remained stable and his $\mathrm{AH}$ prediction based on his bone age improved from 156 $\mathrm{cm}$ to $167.4 \mathrm{~cm}$ during therapy (LoE 4 ).

In one case of the large cohort of patients with $A C A N$ haploinsufficiency (79), the effect of letrozole treatment for one year was reported, resulting in arrested bone maturation (LoE 4). In a recent Chinese study (86), the effect of GnRHa or an AI in addition to rhGH was compared with rhGH alone, but no separate analysis of these two interventions were presented, as discussed earlier (LoE 4).

\subsubsection{Hypothyroidism}

There is one case report on the effect of anastrozole as cotreatment to LT4 treatment in a boy who was diagnosed at 12 years of age with a height of -3.5 SDS (139). After 2 years of LT4, anastrozole was added for 1.5 years because of rapid bone maturation, resulting in a $\mathrm{PAH}$ of $11 \mathrm{~cm}$ below TH. BA advancement slowed and the patient's NAH was $2.4 \mathrm{~cm}$ taller than PAH at start of anastrozole (LoE 4).

\subsubsection{Chronic Kidney Disease}

In a case report, a one year treatment with anastrozole after renal transplantation appeared to have a positive effect on growth and the authors suggested that this strategy should be considered in children who present with significant short stature close to puberty when time for other therapeutic options is limited (140) (LoE 4).

\subsection{The effect of Aromatase Inhibitors in Girls}

For the four rare disorders characterized by hyperestrogenism (aromatase excess syndrome, Peutz-Jeghers syndrome, McCuneAlbright syndrome, and functional follicular ovarian cysts) AIs in girls have been used with modest results (5). Regarding hyperandrogenism, the combination of letrozole and a $\mathrm{GnRHa}$ has been applied to 7 girls with $\mathrm{CAH}$ and $\mathrm{CPP}$, with apparently a good effect on AH (98) (LoE 4).

Most clinicians are hesitant to use AIs in girls in order to increase $\mathrm{AH}$, and in the most recent review AIs were considered "contraindicated in girls with short stature due to concerns about precipitating ovarian cysts with risk of torsion" (3), based on the occurrence of ovarian torsion in patients with congenital aromatase deficiency. Still, a prospective phase 2 a study was performed in 40 girls consecutively referred for early puberty (onset 7.5-9 years) with a PAH $<-2$ or $>1.5$ SD lower than their $\mathrm{TH}$, which compared GnRHa plus anastrozole $(\mathrm{n}=20)$ with GnRHa alone $(n=20)$ for 2 years or until the age of 10 years (141). In the group receiving the combination treatment, $\mathrm{PAH}$ SDS gain was almost double of that observed in the group on GnRHa alone by 12 and 18 months, and reached the maximum of +1.2 SDS $(7.5 \mathrm{~cm})$ vs +0.3 SDS $(1.9 \mathrm{~cm})$ after 2 years, respectively (LoE 2 ).

\subsection{Safety of Aromatase Inhibitors in Childhood and Adolescence}

The use of AIs in male children and adolescents has been associated with several adverse events, probably associated with a decrease of circulating and intracellular estrogens and an increase of circulating androgens due to increased $\mathrm{LH}$ secretion, particularly on letrozole.

Estrogen receptors and aromatase activity are ubiquitously present throughout the body, suggesting that estrogen signaling is crucial for many tissues. The main potential adverse events associated with estrogen deficiency are changes in BMD, bone turnover, lipid metabolism, insulin sensitivity, and cognitive performance $(1,3)$. In fact, adults with estrogen deficiency due to hypogonadism or aromatase deficiency do present with a low BMD. Although in the RCTs no change of BMD was reported (130), a temporary decrease of BMD was noted by Krebs et al. (135).

In the study on the effect of letrozole in boys with ISS, most of whom were prepubertal boys at start of treatment, vertebral anomalies were noted (142). A similar observation was made in a boy treated for 11 years from 4 years of age onward (109). Serum HDL slightly decreased and insulin sensitivity slightly increased (143). No significant adverse effect on cognitive performance was found (1). Increased erythropoiesis was noted in several studies (2, 144-146). A theoretical risk of AIs is that letrozole-induced gonadotropin secretion and ensuing high concentrations of intratesticular testosterone might affect development of seminiferous epithelium (133). In fact, abnormalities of sperm (impaired motility and subnormal morphology) were observed in the boy treated with letrozole for 11 years (109), but not in an RCT on the effect of anastrozole (147).

Multiple adverse events were noted during follow-up of the 151 patients treated with rhGH plus letrozole or anastrozole, including elevated uric acid, decreased HDL, severe acne, excitement, hyperactivity and irritability, a fracture, mild renal dysfunction, inactivity, drowsiness, memory loss and performance decline, mildly abnormal liver function, and granulocytopenia (138). The percentages of knee pain (11$12 \%)$ and impaired fasting glucose (1-2\%) were similar to those in patients on rhGH alone. In another report (2), the severity of acne and hematocrit significantly increased in boys who started treatment in Tanner IV-V. In girls no adverse events were observed (141).

Although no head-to-head comparison is possible, my impression is that adverse events of letrozole are more frequent than of anastrozole.

\section{DISCUSSION AND CONCLUSION}

In general, the scientific evidence for the efficacy of GnRHa or AIs in the treatment of various growth disorders is suboptimal, because of the scarcity of randomized controlled trials up to $\mathrm{AH}$ and conflicting reports. Table 4 shows my subjective impression of the efficacy of GnRHa or AI alone, or various combinations, in particular with rhGH. 
TABLE 4 | Apparent efficacy of different treatment regimens manipulating skeletal maturation for increasing adult height.

\begin{tabular}{|c|c|c|c|c|c|}
\hline & GnRHa alone & GnRHa + rhGH & $\mathrm{GnRHa}+\mathrm{Al}$ & Al alone & $\mathbf{A l}+\mathbf{r h G H}$ \\
\hline CPP & ++ & +1 & \pm & & \\
\hline Hypothyroidism² & \pm & \pm & & & \\
\hline Laron syndrome & \pm & & & & \\
\hline GHD & & $++^{3}$ & & & \pm \\
\hline SGA & & $t^{3}$ & & & \\
\hline ISS & \pm & + in girls, \pm in boys & & \pm & \pm \\
\hline SHOX, NPR2, or ACAN haploinsufficiency & & \pm & & & \pm \\
\hline $\mathrm{CAH}$ & & $+^{3}$ & $\pm^{3}$ & & \pm \\
\hline CDGP & & & & \pm & \pm \\
\hline
\end{tabular}

${ }^{1}$ In case of severely decreased growth velocity during GnRHa therapy.

${ }^{2}$ In case of severe longstanding hypothyroidism and bone age delay.

${ }^{3}$ In case of precocious puberty or when entering puberty at a low height SDS.

++: Treatment considered effective in significantly increasing adult height, based on several good quality studies.

$+:$ Some treatment effect on adult height with reasonable certainty.

+/-: Uncertain treatment effect due to conflicting or limited evidence.

CAH, congenital adrenal hyperplasia; CDGP, constitutional delay of growth and puberty; CPP, central precocious puberty; GHD, growth hormone deficiency; ISS, idiopathic short stature; SGA, small for gestational age.

The efficacy of a GnRHa alone is proven for children with $\mathrm{CPP}$, but less certain for any other condition. The available clinical evidence appears sufficient to conclude that in rhGHtreated children with GHD or SGA and in rhGH-treated girls with ISS who develop CPP or who are short at pubertal onset, $\mathrm{AH}$ can be increased by adding a GnRHa for 2-3 years. Anecdotal reports suggest that a larger effect can be reached with a longer treatment period, for example in girls with ISS and relatively early puberty. However, the potential adverse consequences in terms of bone health and psychosocial development have to be considered.

A combination of rhGH plus GnRHa has also been used for children with several conditions, if PAH SDS was low at the onset of puberty. The effect appears similar among conditions, and close to a gain of $1 \mathrm{SD}(6-7 \mathrm{~cm})$. However, the number of RCTs is low, much of the evidence is derived from uncontrolled studies and case reports, for most conditions rhGH treatment is not registered, and GnRHas can only be prescribed off-label except for CPP. Still, I believe that the similarity between the results in children with the various conditions, particularly children with $\mathrm{CPP}$ on GnRHa treatment with a low height velocity and PAH and those in children with $\mathrm{CAH}$ with a low $\mathrm{PAH}$, render it plausible that growth stimulation by rhGH in combination with low estrogen exposure by a GnRHa provides more time for growth by inhibiting maturation of the epiphyseal growth plates and increases $\mathrm{AH}$. These observations are also in line with the observations on experiments of nature (continued growth and tall AH in disorders where circulating estrogens are low). GnRHa treatment is usually tolerated well, and a modest decrease of BMD appears to be compensated after discontinuation of treatment.

Theoretically, one would expect a similar effect of AIs on growth and skeletal maturation as of GnRHas, but the lack of reported data on $\mathrm{AH}$ make it difficult to estimate the extent of the effect. AIs do have a therapeutic value in a few very rare disorders, but their value in growth disorders, either alone or in combination with $\mathrm{rhGH}$, is still uncertain. In patients with GHD or ISS, co-medication with anastrozole $(103,125)$ may have a similar effect as co-medication with a $\mathrm{GnRHa}$ (45), but the lack of AH data precludes a firm conclusion. Long-term followup of the boys with ISS treated with letrozole have shown that a statistically significant increase of PAH does not always translate to an increased $\mathrm{AH}$ (124). Comparing anastrozole and letrozole co-medication, the results tend to be slightly superior for anastrozole, but this has to be confirmed by an RCT comparing the two compounds directly.

AI treatment leads to increased plasma testosterone, which is considered a psychological advantage for adolescent males but a potential disadvantage for females. Therefore, the use of AIs in adolescence has virtually be confined to boys. The preliminary data on the use of anastrozole in short girls (141) challenge this hypothesis, but this observation needs confirmation.

Regarding safety, GnRHas are considered safe (11), but there is more uncertainty about the safety of AIs, particularly if treatment is given for a long period, and possibly more for letrozole than for anastrozole.

\section{AUTHOR CONTRIBUTIONS}

The author confirms being the sole contributor of this work and has approved it for publication.

\section{ACKNOWLEDGMENTS}

I am grateful to Dr. Christiaan de Bruin and Dr. Sjoerd Joustra (Willem-Alexander Children's Hospital LUMC, Department of Pediatrics, Division of Pediatric Endocrinology) and Prof. Alexander A.L. Jorge (Unidade de Endocrinologia Genetica, Laboratorio de Endocrinologia Celular e Molecular (LIM/25) do Hospital das Clínicas da Faculdade de Medicina da Universidade de Sao Paulo, Sao Paulo, Brazil) for their constructive comments on previous versions of this manuscript. 


\section{REFERENCES}

1. Hero M. Aromatase Inhibitors in the Treatment of Short Stature. Endocr Dev (2016) 30:130-40. doi: 10.1159/000439338

2. Ferris JA, Geffner ME. Are Aromatase Inhibitors in Boys With Predicted Short Stature and/or Rapidly Advancing Bone Age Effective and Safe? J Pediatr Endocrinol Metab (2017) 30(3):311-7. doi: 10.1515/jpem-2016-0219

3. Saroufim R, Eugster EA. Non-GH Agents and Novel Therapeutics in the Management of Short Stature. Indian J Pediatr (2021) 88(12):1209-13. doi: 10.1007/s12098-021-03824-3

4. Allen NG, Krishna KB, Lee PA. Use of Gonadotropin-Releasing Hormone Analogs in Children. Curr Opin Pediatr (2021) 33(4):442-8. doi: 10.1097/ MOP.0000000000001026

5. Wit JM, Hero M, Nunez SB. Aromatase Inhibitors in Pediatrics. Nat Rev Endocrinol (2012) 8(3):135-47. doi: 10.1038/nrendo.2011.161

6. Wit JM, Oostdijk W. Novel Approaches to Short Stature Therapy. Best Pract Res Clin Endocrinol Metab (2015) 29(3):353-66. doi: 10.1016/j.beem. 2015.01.003

7. Burns PB, Rohrich RJ, Chung KC. The Levels of Evidence and Their Role in Evidence-Based Medicine. Plast Reconstr Surg (2011) 128(1):305-10. doi: 10.1097/PRS.0b013e318219c171

8. Baron J, Savendahl L, De Luca F, Dauber A, Phillip M, Wit JM, et al. Short and Tall Stature: A New Paradigm Emerges. Nat Rev Endocrinol (2015) 11 (12):735-46. doi: 10.1038/nrendo.2015.165

9. Weise M, De Levi S, Barnes KM, Gafni RI, Abad V, Baron J. Effects of Estrogen on Growth Plate Senescence and Epiphyseal Fusion. Proc Natl Acad Sci U.S.A. (2001) 98(12):6871-6. doi: 10.1073/pnas.121180498

10. Carel JC, Eugster EA, Rogol A, Ghizzoni L, Palmert MR, Antoniazzi F, et al. Consensus Statement on the Use of Gonadotropin-Releasing Hormone Analogs in Children. Pediatrics (2009) 123(4):e752-62. doi: 10.1542/ peds.2008-1783

11. Bangalore Krishna K, Fuqua JS, Rogol AD, Klein KO, Popovic J, Houk CP, et al. Use of Gonadotropin-Releasing Hormone Analogs in Children: Update by an International Consortium. Horm Res Paediatr (2019) 91(6):357-72. doi: $10.1159 / 000501336$

12. Den Ouden DT, Kroon M, Hoogland PH, Geelhoed-Duijvestijn PH, Wit JM. A 43-Year-Old Male With Untreated Panhypopituitarism Due to Absence of the Pituitary Stalk: From Dwarf to Giant. J Clin Endocrinol Metab (2002) 87 (12):5430-4. doi: $10.1210 /$ jc.2002-020672

13. Faustini-Fustini M, Balestrieri A, Rochira V, Carani C. The Apparent Paradox of Tall Stature With Hypopituitarism: New Insights From an Old Story. J Clin Endocrinol Metab (2003) 88(8):4002-3; author reply 3. doi: 10.1210/jc.2003-030603

14. Smith EP, Boyd J, Frank GR, Takahashi H, Cohen RM, Specker B, et al. Estrogen Resistance Caused by a Mutation in the Estrogen-Receptor Gene in a Man. N Engl J Med (1994) 331(16):1056-61. doi: 10.1056/ NEJM199410203311604

15. Conte FA, Grumbach MM, Ito Y, Fisher CR, Simpson ER. A Syndrome of Female Pseudohermaphrodism, Hypergonadotropic Hypogonadism, and Multicystic Ovaries Associated With Missense Mutations in the Gene Encoding Aromatase (P450arom). J Clin Endocrinol Metab (1994) 78 (6):1287-92. doi: 10.1210/jcem.78.6.8200927

16. Gault EJ, Perry RJ, Cole TJ, Casey S, Paterson WF, Hindmarsh PC, et al. Effect of Oxandrolone and Timing of Pubertal Induction on Final Height in Turner's Syndrome: Randomised, Double Blind, Placebo Controlled Trial. BMJ (2011) 342:d1980. doi: 10.1136/bmj.d1980

17. Ross JL, Cassorla FG, Skerda MC, Valk IM, Loriaux DL, Cutler GB. A Preliminary Study of the Effect of Estrogen Dose on Growth in Turner's Syndrome. N Engl J Med (1983) 3:1104-6. doi: 10.1056/ NEJM198311033091806

18. Caruso-Nicoletti M, Cassorla F, Skerda M, Ross JL, Loriaux DL, Cutler GB Jr. Short Term, Low Dose Estradiol Accelerates Ulnar Growth in Boys. J Clin Endocrinol Metab (1985) 61(5):896-8. doi: 10.1210/jcem-61-5-896

19. Ross JL, Long LM, Skerda M, Cassorla F, Loriaux DL, Cutler GBJr. Growth Response Relationship Between Growth Hormone Dose and Short Term Growth in Patients With Turner's Syndrome. J Clin Endocrinol Metab (1986) 63(4):1028-30. doi: 10.1210/jcem-63-4-1028
20. Ross JL, Cassorla F, Carpenter G, Long LM, Royster MS, Loriaux DL, et al. The Effect of Short Term Treatment With Growth Hormone and Ethinyl Estradiol on Lower Leg Growth Rate in Girls With Turner's Syndrome. J Clin Endocrinol Metab (1988) 67(3):515-8. doi: 10.1210/jcem-67-3-515

21. Ross JL, Quigley CA, Cao D, Feuillan P, Kowal K, Chipman JJ, et al. Growth Hormone Plus Childhood Low-Dose Estrogen in Turner's Syndrome. N Engl J Med (2011) 364(13):1230-42. doi: 10.1056/NEJMoa1005669

22. Venn A, Bruinsma F, Werther G, Pyett P, Baird D, Jones P, et al. Oestrogen Treatment to Reduce the Adult Height of Tall Girls: Long-Term Effects on Fertility. Lancet (2004) 364(9444):1513-8. doi: 10.1016/S0140-6736(04) 17274-7

23. Hendriks AE, Drop SL, Laven JS, Boot AM. Fertility of Tall Girls Treated With High-Dose Estrogen, a Dose-Response Relationship. J Clin Endocrinol Metab (2012) 97(9):3107-14. doi: 10.1210/jc.2012-1078

24. Huttunen H, Varimo T, Huopio H, Voutilainen R, Tenhola S, Miettinen PJ, et al. Serum Testosterone and Oestradiol Predict the Growth Response During Puberty Promoting Treatment. Clin Endocrinol (Oxf) (2021). doi: 10.1111/cen.14605

25. Kish MA. Guide to Development of Practice Guidelines. Clin Infect Dis (2001) 32(6):851-4. doi: 10.1086/319366

26. The AGREE Collaboration. Development and Validation of an International Appraisal Instrument for Assessing the Quality of Clinical Practice Guidelines: The AGREE Project. Qual Saf Health Care (2003) 12(1):1823. doi: $10.1136 / \mathrm{qhc} \cdot 12.1 .18$

27. Yanovski JA, Rose SR, Municchi G, Pescovitz OH, Hill SC, Cassorla FG, et al Treatment With a Luteinizing Hormone-Releasing Hormone Agonist in Adolescents With Short Stature. N Engl J Med (2003) 348(10):908-17. doi: 10.1056/NEJMoa013555

28. Khawaja N, Owaineh H, Batieha A, Frahid O, El-Khateeb M, Ajlouni KM. The Effect of Gonadotropin-Releasing Hormone Analogue on Final Adult Height in Children With Idiopathic Short Stature. Med Princ Pract (2019) 28 (6):509-16. doi: 10.1159/000499929

29. Carel JC, Hay F, Coutant R, Rodrigue D, Chaussain JL. GonadotropinReleasing Hormone Agonist Treatment of Girls With Constitutional Short Stature and Normal Pubertal Development. J Clin Endocrinol Metab (1996) 81(9):3318-22. doi: 10.1210/jcem.81.9.8784090

30. Bouvattier C, Coste J, Rodrigue D, Teinturier C, Carel JC, Chaussain JL, et al Lack of Effect of GnRH Agonists on Final Height in Girls With Advanced Puberty: A Randomized Long-Term Pilot Study. J Clin Endocrinol Metab (1999) 84(10):3575-8. doi: 10.1210/jcem.84.10.6032

31. Cassio A, Cacciari E, Balsamo A, Bal M, Tassinari D. Randomised Trial of LHRH Analogue Treatment on Final Height in Girls With Onset of Puberty Aged 7.5-8.5 Years. Arch Dis Child (1999) 81(4):329-32. doi: 10.1136/ adc.81.4.329

32. Lazar L, Kauli R, Pertzelan A, Phillip M. Gonadotropin-Suppressive Therapy in Girls With Early and Fast Puberty Affects the Pace of Puberty But Not Total Pubertal Growth or Final Height. J Clin Endocrinol Metab (2002) 87 (5):2090-4. doi: 10.1210/jcem.87.5.8481

33. Lampit M, Golander A, Guttmann H, Hochberg Z. Estrogen Mini-Dose Replacement During GnRH Agonist Therapy in Central Precocious Puberty: A Pilot Study. J Clin Endocrinol Metab (2002) 87(2):687-90. doi: 10.1210/ jcem.87.2.8242

34. Vottero A, Pedori S, Verna M, Pagano B, Cappa M, Loche S, et al. Final Height in Girls With Central Idiopathic Precocious Puberty Treated With Gonadotropin-Releasing Hormone Analog and Oxandrolone. J Clin Endocrinol Metab (2006) 91(4):1284-7. doi: 10.1210/jc.2005-1693

35. Tanaka T, Naiki Y, Horikawa R. Combined Treatment With GonadotropinReleasing Hormone Analog and Anabolic Steroid Hormone Increased Pubertal Height Gain and Adult Height in Boys With Early Puberty for Height. Clin Pediatr Endocrinol (2012) 21(2):35-43. doi: 10.1297/cpe.21.35

36. Teng L, Bui H, Bachrach L, Lee P, Gagne N, Deal C, et al. Catch-Up Growth in Severe Juvenile Hypothyroidism: Treatment With a GnRH Analog. J Pediatr Endocrinol Metab (2004) 17(3):345-54. doi: 10.1515/ JPEM.2004.17.3.345

37. El Kholy M, Elsedfy HH. Effect of GnRH Analogue on Height Potential in Patients With Severe Growth Hormone Insensitivity Syndrome Treated With IGF-I. J Pediatr Endocrinol Metab (2011) 24(11-12):983-8. doi 10.1515/JPEM.2011.348 
38. Backeljauw PF, Kuntze J, Frane J, Calikoglu AS, Chernausek SD. Adult and Near-Adult Height in Patients With Severe Insulin-Like Growth Factor-I Deficiency After Long-Term Therapy With Recombinant Human InsulinLike Growth Factor-I. Horm Res Paediatr (2013) 80(1):47-56. doi: 10.1159/ 000351958

39. Cara JF, Kreiter ML, Rosenfield RL. Height Prognosis of Children With True Precocious Puberty and Growth Hormone Deficiency - Effect of Combination Therapy With Gonadotropin Releasing Hormone Agonist and Growth Hormone. J Pediatr (1992) 120:709-15. doi: 10.1016/S00223476(05)80232-X

40. Thomas BC, Stanhope R, Leiper AD. Gonadotropin Releasing Hormone Analogue and Growth Hormone Therapy in Precocious and Premature Puberty Following Cranial Irradiation for Acute Lymphoblastic Leukaemia. Horm Res (1993) 39(1-2):25-9. doi: 10.1159/000182690

41. Adan L, Souberbielle JC, Zucker JM, Pierre-Kahn A, Kalifa C, Brauner R. Adult Height in 24 Patients Treated for Growth Hormone Deficiency and Early Puberty. J Clin Endocrinol Metab (1997) 82(1):229-33. doi: 10.1210/ jc. 82.1 .229

42. Kohn B, Julius JR, Blethen SL. Combined Use of Growth Hormone and Gonadotropin-Releasing Hormone Analogues: The National Cooperative Growth Study Experience. Pediatrics (1999) 104(4 Pt 2):1014-8.

43. Mul D, Wit JM, Oostdijk W, Van den Broeck J. The Effect of Pubertal Delay by GnRH Agonist in GH-Deficient Children on Final Height. J Clin Endocrinol Metab (2001) 86(10):4655-6. doi: 10.1210/jcem.86.10.7910

44. Sas TC, de Ridder MA, Wit JM, Rotteveel J, Oostdijk W, Reeser HM, et al. Adult Height in Children With Growth Hormone Deficiency: A Randomized, Controlled, Growth Hormone Dose-Response Trial. Horm Res Paediatr (2010) 74(3):172-81. doi: 10.1159/000281323

45. Mericq MV, Eggers M, Avila A, Cutler GB Jr, Cassorla F. Near Final Height in Pubertal Growth Hormone (GH)-Deficient Patients Treated With GH Alone or in Combination With Luteinizing Hormone-Releasing Hormone Analog: Results of a Prospective, Randomized Trial. J Clin Endocrinol Metab (2000) 85(2):569-73. doi: 10.1210/jcem.85.2.6343

46. Walenkamp MJ, Pereira AM, Oostdijk W, Stokvis-Brantsma WH, Pfaeffle RW, Blankenstein O, et al. Height Gain With Combined Growth Hormone and Gonadotropin-Releasing Hormone Analog Therapy in Two Pubertal Siblings With a Growth Hormone-Releasing Hormone Receptor Mutation. J Clin Endocrinol Metab (2008) 93(1):204-7. doi: 10.1210/jc.2007-1572

47. Mericq V, Gajardo H, Eggers M, Avila A, Cassorla F. Effects of Treatment With GH Alone or in Combination With LHRH Analog on Bone Mineral Density in Pubertal GH-Deficient Patients. J Clin Endocrinol Metab (2002) 87(1):84-9. doi: 10.1210/jcem.87.1.8148

48. Lazar L, Pollak U, Kalter-Leibovici O, Pertzelan A, Phillip M. Pubertal Course of Persistently Short Children Born Small for Gestational Age (SGA) Compared With Idiopathic Short Children Born Appropriate for Gestational Age (AGA). Eur J Endocrinol (2003) 149(5):425-32. doi: 10.1530/eje.0.1490425

49. Hernandez MI, Martinez-Aguayo A, Cavada G, Pena V, Trejo L, Avila A, et al. Accelerated Early Pubertal Progression, Ovarian Morphology, and Ovarian Function in Prospectively Followed Low Birth Weight (LBW) Girls. J Pediatr Endocrinol Metab (2013) 26(3-4):223-30. doi: 10.1515/jpem-20120345

50. Finken MJJ, van der Steen M, Smeets CCJ, Walenkamp MJE, de Bruin C, Hokken-Koelega ACS, et al. Children Born Small for Gestational Age: Differential Diagnosis, Molecular Genetic Evaluation, and Implications. Endocr Rev (2018) 39(6):851-94. doi: 10.1210/er.2018-00083

51. Lem AJ, van der Kaay DC, de Ridder MA, Bakker-van Waarde WM, van der Hulst FJ, Mulder JC, et al. Adult Height in Short Children Born SGA Treated With Growth Hormone and Gonadotropin Releasing Hormone Analog: Results of a Randomized, Dose-Response GH Trial. J Clin Endocrinol Metab (2012) 97(11):4096-105. doi: 10.1210/jc.2012-1987

52. van der Steen M, Lem AJ, van der Kaay DC, Hokken-Koeelega AC. Puberty and Pubertal Growth in GH-Treated SGA Children: Effects of 2 Years of GnRHa Versus No GnRHa. J Clin Endocrinol Metab (2016) 101(5):2005-12. doi: 10.1210/jc.2016-1317

53. van der Kaay D, Bakker B, van der Hulst F, Mul D, Mulder J, Schroor E, et al. Randomized GH Trial With Two Different Dosages in Combination With a GnRH Analogue in Short Small for Gestational Age Children: Effects on
Metabolic Profile and Serum GH, IGF1, and IGFBP3 Levels. Eur J Endocrinol (2010) 162(5):887-95. doi: 10.1530/EJE-09-1113

54. Lem AJ, Jobse I, van der Kaay DC, de Ridder MA, Raat H, Hokken-Koelega AC. Health-Related Quality of Life in Short Children Born Small for Gestational Age: Effects of Growth Hormone Treatment and Postponement of Puberty. Horm Res Paediatr (2012) 77(3):170-9. doi: $10.1159 / 000337218$

55. van der Steen M, Lem AJ, van der Kaay DC, Hokken-Koelega AC. Insulin Sensitivity and Beta-Cell Function in SGA Children Treated With GH and GnRHa: Results of a Long-Term Trial. J Clin Endocrinol Metab (2016) 101 (2):705-13. doi: 10.1210/jc.2015-3435

56. Goedegebuure WJ, van der Steen M, de With JL, Hokken-Koelega A. Cognition, Health-Related Quality of Life, and Psychosocial Functioning After GH/GnRHa Treatment in Young Adults Born SGA. J Clin Endocrinol Metab (2018) 103(11):3931-8. doi: 10.1210/jc.2018-01463

57. Goedegebuure WJ, van der Steen M, Kerkhof GF, Hokken-Koelega ACS. Longitudinal Study on Metabolic Health in Adults SGA During 5 Years After GH With or Without 2 Years of GnRHa Treatment. J Clin Endocrinol Metab (2020) 105(8):dgaa287. doi: 10.1210/clinem/dgaa287

58. van Gool SA, Kamp GA, Visser-van Balen H, Mul D, Waelkens JJ, Jansen M, et al. Final Height Outcome After Three Years of Growth Hormone and Gonadotropin-Releasing Hormone Agonist Treatment in Short Adolescents With Relatively Early Puberty. J Clin Endocrinol Metab (2007) 92(4):1402-8. doi: 10.1210/jc.2006-2272

59. Adler E, Lambert AS, Bouvattier C, Thomas-Teinturier C, Rothenbuhler A, de Boissieu P, et al. Determinants of Final Height in Patients Born Small for Gestational Age Treated With Recombinant Growth Hormone. Horm Res Paediatr (2021) 94(1-2):52-62. doi: 10.1159/000516557

60. Binder G, Liebl M, Woelfle J, Eggermann T, Blumenstock G, Schweizer R. Adult Height and Epigenotype in Children With Silver-Russell Syndrome Treated With GH. Horm Res Paediatr (2013) 80(3):193-200. doi: 10.1159/ 000354658

61. Wakeling EL, Brioude F, Lokulo-Sodipe O, O'Connell SM, Salem J, Bliek J, et al. Diagnosis and Management of Silver-Russell Syndrome: First International Consensus Statement. Nat Rev Endocrinol (2017) 13(2):10524. doi: $10.1038 /$ nrendo. 2016.138

62. Netchine I, van der Steen M, Lopez-Bermejo A, Koledova E, Maghnie M. New Horizons in Short Children Born Small for Gestational Age. Front Pediatr (2021) 9:655931. doi: 10.3389/fped.2021.655931

63. Ranke MB, Reiter EO, Price DA. Idiopathic Growth Hormone Deficiency in KIGS: Selected Aspects. In: MB R, DA Price and EO Reiter, editors. Growth Hormone Therapy in Pediatrics - 20 Years Of KIGS. Basel: Karger (2007). p. $116-35$.

64. Job JC, Toublanc JE, Landier F. Growth of Short Normal Children in Puberty Treated for 3 Years With Growth Hormone Alone or in Association With Gonadotropin- Releasing Hormone Agonist. Horm Res (1994) 41(5-6):177-84. doi: 10.1159/000183889

65. Saggese G, Cesaretti G, Barsanti S, Rossi A. Combination Treatment With Growth Hormone and Gonadotropin-Releasing Hormone Analogs in Short Normal Girls. J Pediatr (1995) 126(3):468-73. doi: 10.1016/S0022-3476(95) 70473-6

66. Tanaka T, Satoh M, Yasunaga T, Horikawa R, Tanae A, Hibi I. GH and GnRH Analog Treatment in Children Who Enter Puberty at Short Stature. J Pediatr Endocrinol Metab (1997) 10(6):623-8. doi: 10.1515/ JPEM.1997.10.6.623

67. Toumba M, Kokotsis V, Savva SC, Skordis N. Expensive Therapies in Children: Benefit Versus Cost of Combined Treatment of Recombinant Human Growth Hormone and Gonadotropin-Releasing Hormone Analogue in Girls With Poor Height Potential. J Pediatr Endocrinol Metab (2014) 27(3-4):311-6. doi: 10.1515/jpem-2013-0210

68. Balducci R, Toscano V, Mangiantini A, Municchi G, Vaccaro F, Picone S, et al. Adult Height in Short Normal Adolescent Girls Treated With Gonadotropin-Releasing Hormone Analog and Growth Hormone. J Clin Endocrinol Metab (1995) 80(12):3596-600. doi: 10.1210/jcem.80.12.8530605

69. Li S, Wang X, Zhao Y, Ji W, Mao J, Nie M, et al. Combined Therapy With GnRH Analogue and Growth Hormone Increases Adult Height in Children With Short Stature and Normal Pubertal Onset. Endocrine (2020) 69 (3):615-24. doi: 10.1007/s12020-020-02375-5 
70. Lanes R, Gunczler P. Final Height After Combined Growth Hormone and Gonadotrophin-Releasing Hormone Analogue Therapy in Short Healthy Children Entering Into Normally Timed Puberty. Clin Endocrinol (Oxf) (1998) 49(2):197-202. doi: 10.1046/j.1365-2265.1998.00499.x

71. Pasquino AM, Pucarelli I, Roggini M, Segni M. Adult Height in Short Normal Girls Treated With Gonadotropin-Releasing Hormone Analogs and Growth Hormone. J Clin Endocrinol Metab (2000) 85(2):619-22. doi: 10.1210/jcem.85.2.6387

72. Benabbad I, Rosilio M, Tauber M, Paris E, Paulsen A, Berggren L, et al. Growth Hormone in Combination With Leuprorelin in Pubertal Children With Idiopathic Short Stature. Endocr Connect (2018) 7(5):708-18. doi: 10.1530/EC-18-0137

73. Lazar L, Levy S, Oron T, Meyerovitch J, de Vries L, Shalitin S, et al. The Beneficial Effect of Combined GH/GnRHa Therapy in Increasing Adult Height Outcome in Children With ISS. J Clin Endocrinol Metab (2019) 104 (8):3287-95. doi: 10.1210/jc.2019-00233

74. Visser-van Balen H, Geenen R, Kamp GA, Huisman J, Wit JM, Sinnema G. Long-Term Psychosocial Consequences of Hormone Treatment for Short Stature. Acta Paediatr (2007) 96(5):715-9. doi: 10.1111/j.1651-2227. 2007.00235.x

75. Tuvemo T, Jonsson B, Gustafsson J, Albertsson-Wikland K, Aronson AS, Hager A, et al. Final Height After Combined Growth Hormone and GnRH Analogue Treatment in Adopted Girls With Early Puberty. Acta Paediatr (2004) 93(11):1456-62. doi: 10.1111/j.1651-2227.2004.tb02629.x

76. Mul D, Oostdijk W, Waelkens JJ, Drop SL. Final Height After Treatment of Early Puberty in Short Adopted Girls With Gonadotrophin Releasing Hormone Agonist With or Without Growth Hormone. Clin Endocrinol (Oxf) (2005) 63(2):185-90. doi: 10.1111/j.1365-2265.2005.02323.x

77. Scalco RC, Melo SS, Pugliese-Pires PN, Funari MF, Nishi MY, Arnhold IJ, et al. Effectiveness of the Combined Recombinant Human Growth Hormone and Gonadotropin-Releasing Hormone Analog Therapy in Pubertal Patients With Short Stature Due to SHOX Deficiency. J Clin Endocrinol Metab (2010) 95(1):328-32. doi: 10.1210/jc.2009-1577

78. Hanley PC, Kanwar HS, Martineau C, Levine MA. Short Stature Is Progressive in Patients With Heterozygous NPR2 Mutations. J Clin Endocrinol Metab (2020) 105(10):3190-202. doi: 10.1210/clinem/dgaa491

79. Gkourogianni A, Andrew M, Tyzinski L, Crocker M, Douglas J, Dunbar N, et al. Clinical Characterization of Patients With Autosomal Dominant Short Stature Due to Aggrecan Mutations. J Clin Endocrinol Metab (2017) 102 (2):460-9. doi: 10.1210/jc.2016-3313

80. Ranke MB, Wit JM. Growth Hormone - Past, Present and Future. Nat Rev Endocrinol (2018) 14(5):285-300. doi: 10.1038/nrendo.2018.22

81. Ogata T, Onigata K, Hotsubo T, Matsuo N, Rappold G. Growth Hormone and Gonadotropin-Releasing Hormone Analog Therapy in Haploinsufficiency of SHOX. Endocr J (2001) 48(3):317-22. doi: 10.1507/ endocr. 48.317

82. Ke X, Liang H, Miao H, Yang H, Wang L, Gong F, et al. Clinical Characteristics of Short-Stature Patients With an NPR2 Mutation and the Therapeutic Response to rhGH. J Clin Endocrinol Metab (2021) 106(2):43141. doi: $10.1210 /$ clinem/dgaa 842

83. Vasques GA, Amano N, Docko AJ, Funari MF, Quedas EP, Nishi MY, et al. Heterozygous Mutations in Natriuretic Peptide Receptor-B (NPR2) Gene as a Cause of Short Stature in Patients Initially Classified as Idiopathic Short Stature. J Clin Endocrinol Metab (2013) 98(10):E1636-E44. doi: 10.1210/ jc.2013-2142

84. Wang SR, Jacobsen CM, Carmichael H, Edmund AB, Robinson JW, Olney RC, et al. Heterozygous Mutations in Natriuretic Peptide Receptor-B (NPR2) Gene as a Cause of Short Stature. Hum Mutat (2015) 36(4):47481. doi: 10.1002/humu.22773

85. Lin L, Li M, Luo J, Li P, Zhou S, Yang Y, et al. A High Proportion of Novel ACAN Mutations and Their Prevalence in a Large Cohort of Chinese Short Stature Children. J Clin Endocrinol Metab (2021) 106(7):e2711-9. doi: 10.1210/clinem/dgab088

86. Liang H, Miao H, Pan H, Yang H, Gong F, Duan L, et al. Growth-Promoting Therapies May Be Useful In Short Stature Patients With Nonspecific Skeletal Abnormalities Caused By Acan Heterozygous Mutations: Six Chinese Cases And Literature Review. Endocr Pract (2020) 26(11):1255-68. doi: 10.4158/ EP-2019-0518
87. Pasquino AM, Pucarelli I, Segni M, Matrunola M, Cerroni F, Cerrone F. Adult Height in Girls With Central Precocious Puberty Treated With Gonadotropin-Releasing Hormone Analogues and Growth Hormone. J Clin Endocrinol Metab (1999) 84(2):449-52. doi: 10.1210/jcem.84.2.5431

88. Pucarelli I, Segni M, Ortore M, Arcadi E, Pasquino AM. Effects of Combined Gonadotropin-Releasing Hormone Agonist and Growth Hormone Therapy on Adult Height in Precocious Puberty: A Further Contribution. J Pediatr Endocrinol Metab (2003) 16(7):1005-10. doi: 10.1515/JPEM.2003.16.7.1005

89. Liu S, Liu Q, Cheng X, Luo Y, Wen Y. Effects and Safety of Combination Therapy With Gonadotropin-Releasing Hormone Analogue and Growth Hormone in Girls With Idiopathic Central Precocious Puberty: A MetaAnalysis. J Endocrinol Invest (2016) 39(10):1167-78. doi: 10.1007/s40618016-0486-9

90. Wang M, Zhang Y, Lan D, Hill JW. The Efficacy of GnRHa Alone or in Combination With rhGH for the Treatment of Chinese Children With Central Precocious Puberty. Sci Rep (2016) 6:24259. doi: 10.1038/srep24259

91. Fu J, Zhang J, Chen R, Ma X, Wang C, Chen L, et al. Long-Term Outcomes of Treatments for Central Precocious Puberty or Early and Fast Puberty in Chinese Girls. J Clin Endocrinol Metab (2020) 105(3):dgz027. doi: 10.1210/ jcem.86.4.7412

92. Speiser PW, Azziz R, Baskin LS, Ghizzoni L, Hensle TW, Merke DP, et al. Congenital Adrenal Hyperplasia Due to Steroid 21-Hydroxylase Deficiency: An Endocrine Society Clinical Practice Guideline. J Clin Endocrinol Metab (2010) 95(9):4133-60. doi: 10.1210/jc.2009-2631

93. Bretones P, Riche B, Pichot E, David M, Roy P, Tardy V, et al. Growth Curves for Congenital Adrenal Hyperplasia From a National Retrospective Cohort. J Pediatr Endocrinol Metab (2016) 29(12):1379-88. doi: 10.1515/ jpem-2016-0156

94. Quintos JB, Vogiatzi MG, Harbison MD, New MI. Growth Hormone Therapy Alone or in Combination With Gonadotropin-Releasing Hormone Analog Therapy to Improve the Height Deficit in Children With Congenital Adrenal Hyperplasia. J Clin Endocrinol Metab (2001) 86 (4):1511-7. doi: 10.1136/qhc.12.1.18

95. Lin-Su K, Vogiatzi MG, Marshall I, Harbison MD, Macapagal MC, Betensky B, et al. Treatment With Growth Hormone and Luteinizing Hormone Releasing Hormone Analog Improves Final Adult Height in Children With Congenital Adrenal Hyperplasia. J Clin Endocrinol Metab (2005) 90 (6):3318-25. doi: 10.1210/jc.2004-2128

96. Lin-Su K, Harbison MD, Lekarev O, Vogiatzi MG, New MI. Final Adult Height in Children With Congenital Adrenal Hyperplasia Treated With Growth Hormone. J Clin Endocrinol Metab (2011) 96(6):1710-7. doi: 10.1210/jc.2010-2699

97. Longui CA, Kochi C, Calliari LE, Modkovski MB, Soares M, Alves EF, et al. Near-Final Height in Patients With Congenital Adrenal Hyperplasia Treated With Combined Therapy Using GH and GnRHa. Arq Bras Endocrinol Metabol (2011) 55(8):661-4. doi: 10.1590/S0004-27302011000800023

98. Juan L, Huamei M, Zhe S, Yanhong L, Hongshan C, Qiuli C, et al. Near-Final Height in 82 Chinese Patients With Congenital Adrenal Hyperplasia Due to Classic 21-Hydroxylase Deficiency: A Single-Center Study From China. J Pediatr Endocrinol Metab (2016) 29(7):841-8. doi: 10.1515/jpem-2015-0406

99. Xi W, Mao J, Li S, Zhao Y, Nie M, Yu B, et al. Aromatase Inhibitor Increases the Height of Patients With Congenital Adrenal Hyperplasia Due to 21Hydroxylase Deficiency. Endocr Pract (2020) 26(9):997-1002. doi: 10.4158/ EP-2019-0610

100. Quintos JB, Salas M. Use of Growth Hormone and Gonadotropin Releasing Hormone Agonist in Addition to L-Thyroxine to Attain Normal Adult Height in Two Patients With Severe Hashimoto's Thyroiditis. J Pediatr Endocrinol Metab (2005) 18(5):515-21. doi: 10.1515/JPEM.2005.18.5.515

101. Sendur MA, Aksoy S, Zengin N, Altundag K. Comparative Efficacy Study of 5-Year Letrozole or Anastrozole in Postmenopausal Hormone ReceptorPositive Early Breast Cancer. J BUON (2013) 18(4):838-44.

102. Ellis MJ, Suman VJ, Hoog J, Lin L, Snider J, Prat A, et al. Randomized Phase II Neoadjuvant Comparison Between Letrozole, Anastrozole, and Exemestane for Postmenopausal Women With Estrogen Receptor-Rich Stage 2 to 3 Breast Cancer: Clinical and Biomarker Outcomes and Predictive Value of the Baseline PAM50-Based Intrinsic SubtypeACOSOG Z1031. J Clin Oncol (2011) 29(17):2342-9. doi: 10.1200/ JCO.2010.31.6950 
103. Mauras N, Ross JL, Gagliardi P, Yu YM, Hossain J, Permuy J, et al. Randomized Trial of Aromatase Inhibitors, Growth Hormone, or Combination in Pubertal Boys With Idiopathic, Short Stature. J Clin Endocrinol Metab (2016) 101(12):4984-93. doi: 10.1210/jc.2016-2891

104. Simoes-Pereira J, Santos F, Lopes L, Limbert C. Prepubertal Gynaecomastia in a Boy With Peutz-Jeghers Syndrome: Managing the Aromatase Overexpression. J Pediatr Endocrinol Metab (2018) 31(10):1149-54. doi: 10.1515/jpem-2017-0455

105. Leschek EW, Flor AC, Bryant JC, Jones JV, Barnes KM, Cutler GBJr. Effect of Antiandrogen, Aromatase Inhibitor, and Gonadotropin-Releasing Hormone Analog on Adult Height in Familial Male Precocious Puberty. J Pediatr (2017) 190:229-35. doi: 10.1016/j.jpeds.2017.07.047

106. Lane LC, Flowers J, Johnstone H, Cheetham T. Adult Height in Patients With Familial Male-Limited Precocious Puberty and the Role of an Aromatase Inhibitor in Patient Management. J Pediatr Endocrinol Metab (2018) 31(5):551-60. doi: 10.1515/jpem-2017-0363

107. Merke DP, Keil MF, Jones JV, Fields J, Hill S, Cutler GBJr. Flutamide, Testolactone, and Reduced Hydrocortisone Dose Maintain Normal Growth Velocity and Bone Maturation Despite Elevated Androgen Levels in Children With Congenital Adrenal Hyperplasia. J Clin Endocrinol Metab (2000) 85(3):1114-20. doi: 10.1210/jcem.85.3.6462

108. Goedegebuure WJ, Hokken-Koelega ACS. Aromatase Inhibitor as Treatment for Severely Advanced Bone Age in Congenital Adrenal Hyperplasia: A Case Report. Horm Res Paediatr (2019) 92(3):209-13. doi: 10.1159/000501746

109. Atay Z, Turan S, Bugdayci O, Guran T, Bereket A. Restoration of Height After 11 Years of Letrozole Treatment in 11beta-Hydroxylase Deficiency. Horm Res Paediatr (2019) 92(3):203-8. doi: 10.1159/000501456

110. Nour MA, Pacaud D. Height Augmentation in 11beta-Hydroxylase Deficiency Congenital Adrenal Hyperplasia. Int J Pediatr Endocrinol (2015) 2015(1):12. doi: 10.1186/s13633-015-0008-0

111. Hawton K, Walton-Betancourth S, Rumsby G, Raine J, Dattani M. Growth Hormone With Aromatase Inhibitor May Improve Height in CYP11B1 Congenital Adrenal Hyperplasia. Pediatrics (2017) 139(2):e20160730. doi: 10.1542/peds.2016-0730

112. Kanakis GA, Nordkap L, Bang AK, Calogero AE, Bartfai G, Corona G, et al. EAA Clinical Practice Guidelines-Gynecomastia Evaluation and Management. Andrology (2019) 7(6):778-93. doi: 10.1111/andr.12636

113. Morishima A, Grumbach MM, Simpson ER, Fisher C, Qin K. Aromatase Deficiency in Male and Female Siblings Caused by a Novel Mutation and the Physiological Role of Estrogens. J Clin Endocrinol Metab (1995) 80 (12):3689-98. doi: 10.1210/jcem.80.12.8530621

114. Carani C, Qin K, Simoni M, Faustini-Fustini M, Serpente S, Boyd J, et al. Effect of Testosterone and Estradiol in a Man With Aromatase Deficiency. N Engl J Med (1997) 337(2):91-5. doi: 10.1056/NEJM199707103370204

115. Bilezikian JP, Morishima A, Bell J, Grumbach MM. Increased Bone Mass as a Result of Estrogen Therapy in a Man With Aromatase Deficiency. N Engl J Med (1998) 339(9):599-603. doi: 10.1056/NEJM199808273390905

116. Herrmann BL, Saller B, Janssen OE, Gocke P, Bockisch A, Sperling H, et al. Impact of Estrogen Replacement Therapy in a Male With Congenital Aromatase Deficiency Caused by a Novel Mutation in the CYP19 Gene. $J$ Clin Endocrinol Metab (2002) 87(12):5476-84. doi: 10.1210/jc.2002-020498

117. McGrath N, O'Grady MJ. Aromatase Inhibitors for Short Stature in Male Children and Adolescents. Cochrane Database Syst Rev (2015) 10): CD010888. doi: 10.1002/14651858.CD010888.pub2

118. Neely EK, Kumar RB, Payne SL, Ranadive SA, Suchet DI. Letrozole vs Anastrozole for Height Augmentation in Short Pubertal Males: First Year Data. J Clin Endocrinol Metab (2014) 99(11):4086-93. doi: 10.1210/jc.2014-2432

119. Shulman DI, Francis GL, Palmert MR, Eugster EA. Use of Aromatase Inhibitors in Children and Adolescents With Disorders of Growth and Adolescent Development. Pediatrics (2008) 121(4):e975-e83. doi: 10.1542/ peds.2007-2081

120. Geffner ME. For Debate: Aromatase Inhibitors to Augment Height: Have We Lost Our Inhibitions? Pediatr Endocrinol Rev (2008) 5(3):756-9.

121. Geffner ME. Aromatase Inhibitors to Augment Height: Continued Caution and Study Required. J Clin Res Pediatr Endocrinol (2009) 1(6):256-61. doi: 10.4274/jcrpe.v1i6.256

122. Dunkel L. Off-Label Use of Aromatase Inhibitors to Promote Taller Stature: Is it Safe. Horm Res Paediatr (2010) 74(6):436-7. doi: 10.1159/000317434
123. Hero M, Norjavaara E, Dunkel L. Inhibition of Estrogen Biosynthesis With a Potent Aromatase Inhibitor Increases Predicted Adult Height in Boys With Idiopathic Short Stature: A Randomized Controlled Trial. J Clin Endocrinol Metab (2005) 90(12):6396-402. doi: 10.1210/jc.2005-1392

124. Varimo T, Toiviainen-Salo S, Raivio T, Kerttula L, Dunkel L, Hero M. Letrozole Monotherapy in Pre- and Early-Pubertal Boys Does Not Increase Adult Height. Front Endocrinol (Lausanne) (2019) 10:201. doi: 10.3389/ fendo.2019.00201

125. Mauras N, Gonzalez de PL, Hsiang HY, Desrosiers P, Rapaport R, Schwartz ID, et al. Anastrozole Increases Predicted Adult Height of Short Adolescent Males Treated With Growth Hormone: A Randomized, Placebo-Controlled, Multicenter Trial for One to Three Years. J Clin Endocrinol Metab (2008) 93 (3):823-31. doi: 10.1210/jc.2007-1559

126. Rothenbuhler A, Linglart A, Bougneres P. A Randomized Pilot Trial of Growth Hormone With Anastrozole Versus Growth Hormone Alone, Starting at the Very End of Puberty in Adolescents With Idiopathic Short Stature. Int J Pediatr Endocrinol (2015) 2015(1):4. doi: 10.1186/1687-9856-2015-4

127. Miller BS, Ross J, Ostrow V. Height Outcomes in Children With Growth Hormone Deficiency and Idiopathic Short Stature Treated Concomitantly With Growth Hormone and Aromatase Inhibitor Therapy: Data From the ANSWER Program. Int J Pediatr Endocrinol (2020) 2020:19. doi: 10.1186/s13633-020-00089-z

128. Wickman S, Sipila I, Ankarberg-Lindgren C, Norjavaara E, Dunkel L. A Specific Aromatase Inhibitor and Potential Increase in Adult Height in Boys With Delayed Puberty: A Randomised Controlled Trial. Lancet (2001) 357 (9270):1743-8. doi: 10.1016/S0140-6736(00)04895-9

129. Hero M, Wickman S, Dunkel L. Treatment With the Aromatase Inhibitor Letrozole During Adolescence Increases Near-Final Height in Boys With Constitutional Delay of Puberty. Clin Endocrinol (Oxf) (2006) 64(5):510-3. doi: 10.1111/j.1365-2265.2006.02499.x

130. Hero M, Makitie O, Kroger H, Nousiainen E, Toiviainen-Salo S, Dunkel L. Impact of Aromatase Inhibitor Therapy on Bone Turnover, Cortical Bone Growth and Vertebral Morphology in Pre- and Peripubertal Boys With Idiopathic Short Stature. Horm Res (2009) 71(5):290-7. doi: 10.1159/000208803

131. Salehpour S, Alipour P, Razzaghy-Azar M, Ardeshirpour L, Shamshiri A, Monfared MF, et al. A Double-Blind, Placebo-Controlled Comparison of Letrozole to Oxandrolone Effects Upon Growth and Puberty of Children With Constitutional Delay of Puberty and Idiopathic Short Stature. Horm Res Paediatr (2010) 74(6):428-35. doi: 10.1159/000315482

132. Rohani F, Asadi R, Mirboluk AA, Soheilipour F. Letrozole Effect on Final Height of Patients With Constitutional Delay of Growth and Puberty. Med Arch (2019) 73(5):307-10. doi: 10.5455/medarh.2019.73.307-310

133. Varimo T, Huopio H, Kariola L, Tenhola S, Voutilainen R, Toppari J, et al. Letrozole Versus Testosterone for Promotion of Endogenous Puberty in Boys With Constitutional Delay of Growth and Puberty: A Randomised Controlled Phase 3 Trial. Lancet Child Adolesc Health (2019) 3(2):109-20. doi: 10.1016/S2352-4642(18)30377-8

134. Zhou P, Shah B, Prasad K, David R. Letrozole Significantly Improves Growth Potential in a Pubertal Boy With Growth Hormone Deficiency. Pediatrics (2005) 115(2):e245-e8. doi: 10.1542/peds.2004-1536

135. Krebs A, Moske-Eick O, Doerfer J, Roemer-Pergher C, Werf-Grohmann N, Schwab KO. Marked Increase of Final Height by Long-Term Aromatase Inhibition in a Boy With Idiopathic Short Stature. J Pediatr Endocrinol Metab (2012) 25(5-6):581-5. doi: 10.1515/jpem-2011-0435

136. Bullinger M, Bloemeke J, Mericq V, Sommer R, Gaete X, Ross JL, et al. Quality of Life in Adolescent Boys With Idiopathic Short Stature: Positive Impact of Growth Hormone and Aromatase Inhibitors. Horm Res Paediatr (2018) 90(6):381-92. doi: 10.1159/000496353

137. Pedrosa LF, de Oliveira JM, Thome PRV, Kochi C, Damiani D, Longui CA. Height Increment and Laboratory Profile of Boys Treated With Aromatase Inhibitors With or Without Growth Hormone. Horm Metab Res (2017) 49 (10):778-85. doi: 10.1055/s-0043-116944

138. Kong Y, Chen H, Liang L, Zheng M, Fang Y, Wang C. Aromatase Inhibitors Combined With Growth Hormone in Treatment of Adolescent Boys With Short Stature. Zhejiang Da Xue Xue Bao Yi Xue Ban (2020) 49(3):283-90. doi: 10.3785 /j.issn.1008-9292.2020.04.12

139. Hodax JK, Topor LS, Bialo SR, Quintos JB. Anastrozole Improves Final Adult Height in Severe Hypothyroidism With Rapid Pubertal Progression. J Endocr Soc (2021) 5(5):bvab025. doi: 10.1210/jendso/bvab025 
140. Mendley SR, Spyropoulos F, Counts DR. Short Stature in Chronic Kidney Disease Treated With Growth Hormone and an Aromatase Inhibitor. Case Rep Pediatr (2015) 2015:738571. doi: 10.1155/2015/738571

141. Papadimitriou DT, Dermitzaki E, Papagianni M, Papaioannou G, Papaevangelou V, Papadimitriou A. Anastrozole Plus Leuprorelin in Early Maturing Girls With Compromised Growth: The "GAIL" Study. J Endocrinol Invest (2016) 39(4):439-46. doi: 10.1007/s40618-015-0399-z

142. Hero M, Toiviainen-Salo S, Wickman S, Makitie O, Dunkel L. Vertebral Morphology in Aromatase Inhibitor-Treated Males With Idiopathic Short Stature or Constitutional Delay of Puberty. J Bone Miner Res (2010) 25(7):1536-43. doi: 10.1002/jbmr.56

143. Hero M, Ankarberg-Lindgren C, Taskinen MR, Dunkel L. Blockade of Oestrogen Biosynthesis in Peripubertal Boys: Effects on Lipid Metabolism, Insulin Sensitivity, and Body Composition. Eur J Endocrinol (2006) 155 (3):453-60. doi: 10.1530/eje.1.02226

144. Hero M, Wickman S, Hanhijarvi R, Siimes MA, Dunkel L. Pubertal Upregulation of Erythropoiesis in Boys Is Determined Primarily by Androgen. J Pediatr (2005) 146(2):245-52. doi: 10.1016/j.jpeds.2004.09.002

145. Diaz-Thomas A, Shulman D. Use of Aromatase Inhibitors in Children and Adolescents: What's New? Curr Opin Pediatr (2010) 22(4):501-7. doi: 10.1097/MOP.0b013e32833ab888

146. Shams K, Cameo T, Fennoy I, Hassoun AA, Lerner SE, Aranoff GS, et al. Outcome Analysis of Aromatase Inhibitor Therapy to Increase Adult Height in Males With Predicted Short Adult Stature and/or Rapid Pubertal Progress:
A Retrospective Chart Review. J Pediatr Endocrinol Metab (2014) 27(78):725-30. doi: 10.1515/jpem-2013-0470

147. Mauras N, Bell J, Snow BG, Winslow KL. Sperm Analysis in Growth Hormone-Deficient Adolescents Previously Treated With an Aromatase Inhibitor: Comparison With Normal Controls. Fertil Steril (2005) 84 (1):239-42. doi: 10.1016/j.fertnstert.2005.02.012

Conflict of Interest: The author declares that the research was conducted in the absence of any commercial or financial relationships that could be construed as a potential conflict of interest.

Publisher's Note: All claims expressed in this article are solely those of the authors and do not necessarily represent those of their affiliated organizations, or those of the publisher, the editors and the reviewers. Any product that may be evaluated in this article, or claim that may be made by its manufacturer, is not guaranteed or endorsed by the publisher.

Copyright $\odot 2021$ Wit. This is an open-access article distributed under the terms of the Creative Commons Attribution License (CC BY). The use, distribution or reproduction in other forums is permitted, provided the original author(s) and the copyright owner(s) are credited and that the original publication in this journal is cited, in accordance with accepted academic practice. No use, distribution or reproduction is permitted which does not comply with these terms. 